\title{
CREDIT FRICTIONS AND 'SUDDEN STOPS' IN SMALL OPEN ECONOMIES: AN EQUILIBRIUM BUSINESS CYCLE FRAMEWORK FOR EMERGING MARKETS CRISES
}

\author{
Cristina Arellano \\ Enrique G. Mendoza \\ Working Paper 8880 \\ http://www.nber.org/papers/w8880
NATIONAL BUREAU OF ECONOMIC RESEARCH
1050 Massachusetts Avenue
Cambridge, MA 02138
April 2002

Comments and suggestions from Fernando Alvarez, Franz Hamann, Jonathan Heatcote, Alejandro Izquierdo, Urban Jermann, Pedro Oviedo, Fabrizio Perri, Katherine Smith, Diego Valderrama and Stan Zin are gratefully acknowledged. Mendoza also thanks the Research Department of the Inter-American Development Bank, where part of this article was written. The views expressed herein are those of the authors and not necessarily those of the National Bureau of Economic Research.

(C) 2002 by Cristina Arellano and Enrique G. Mendoza. All rights reserved. Short sections of text, not to exceed two paragraphs, may be quoted without explicit permission provided that full credit, including (C) notice, is given to the source. 
Credit Frictions and 'Sudden Stops' in Small Open Economies:

An Equilibrium Business Cycle Framework for Emerging Markets Crises

Cristina Arellano and Enrique G. Mendoza

NBER Working Paper No. 8880

April 2002

JEL No. F41, F32, E44, D52

\begin{abstract}
Financial frictions are a central element of most of the models that the literature on emerging markets crises has proposed for explaining the 'Sudden Stop' phenomenon. To date, few studies have aimed to examine the quantitative implications of these models and to integrate them with an equilibrium business cycle framework for emerging economies. This paper surveys these studies viewing them as ability-to-pay and willingness-to-pay variations of a framework that adds occasionally binding borrowing constraints to the small open economy real-business-cycle model. A common feature of the different models is that agents factor in the risk of future Sudden Stops in their optimal plans, so that equilibrium allocations and prices are distorted even when credit constraints do not bind. Sudden Stops are a property of the unique, flexible-price competitive equilibrium of these models that occurs in a particular region of the state space in which negative shocks make borrowing constraints bind. The resulting nonlinear effects imply that solving the models requires non-linear numerical methods, which are described in the survey. The results show that the models can yield relatively infrequent Sudden Stops with large current account reversals and deep recessions nested within smoother business cycles. Still, research in this area is at an early stage and this survey aims to stimulate further work.
\end{abstract}

Cristina Arellano

Department of Economics

Social Sciences Building

Duke University

Durham, NC 27708-0097
Enrique G. Mendoza

Department of Economics

University of Maryland

College Park, MD 20742

and NBER

mendozae@econ.duke.edu 


\section{Introduction}

The severity of the financial and economic crisis that hit Mexico after the devaluation of the peso in December of 1994, and the unprecedented “Tequila Effect” by which Mexico's financial woes "infected" emerging markets worldwide were a harbinger of a period of intense turbulence in international capital markets. Seven years later, in December 2001 a major crisis broke out in Argentina with an explosive combination of sovereign default, massive currency devaluation and collapse of production and aggregate demand. In the seven years separating these two crises, similar crises engulfed nearly all of the so-called "emerging markets," including Hong Kong, Korea, Indonesia, Malaysia, Thailand, Russia, Colombia, Ecuador, Brazil, and Turkey. Interestingly, devaluation itself proved not to be a prerequisite for these crises, as illustrated by the experiences of Argentina in 1995, Hong Kong in 1997 or Chile in 1999. Contagion effects similar to the Tequila Effect were also a recurrent phenomenon, as crises spread quickly to the capital markets of countries with no apparent economic linkages to countries in crisis. A favorite example is the correction in U.S. equity prices in the Fall of 1998 that resulted from the wave of margin calls on global investors triggered by the Russian default. The systemic nature of this correction forced the U.S. Federal Reserve to lower interest rates and coordinate the orderly collapse of hedge fund Long Term Capital Management.

Emerging-markets crises are characterized by a set of striking empirical regularities that Calvo (1998) labeled the "Sudden Stop" phenomenon. These empirical regularities include: (a) a sudden loss of access to international capital markets, (b) a large reversal of the current account deficit, (c) a collapse of domestic production and aggregate demand, and (d) sharp corrections in asset prices and in the prices of non-traded goods relative to traded goods. Figures 1-3 illustrate 
some of these stylized facts for Argentina, Korea, Mexico, Russia and Turkey. ${ }^{1}$ Figure 1 shows recent time series data for each country's current account as a share of GDP. Sudden Stops are displayed in these plots as sudden, large swings of the current account that in most cases exceeded five percentage points of GDP. Figure 2 shows data on consumption growth as an indicator of real economic activity. These plots show that Sudden Stops are associated with a collapse in the real sector of the economy. Figure 3 provides information on two key financial indicators for each country, the price of domestic equity (valued in U.S. dollars) and the spread of the yield in JP Morgan's Emerging Markets Bond Index Plus (EMBI+) for each country relative to U.S. Treasury bills. Large declines in equity prices and sudden, sharp increases in EMBI+ spreads are features of Sudden Stops, with equity prices often leading the surge of the EMBI+ spread at the monthly frequency.

The Sudden Stops phenomenon is seriously at odds with the predictions of the majority of existing models of current account determination and business cycles in small open economies, both frictionless Real Business Cycle (RBC) models and models with nominal rigidities. In these models, international capital markets provide the means for small open economies to borrow in order to smooth consumption when "bad" states of nature materialize, and to share the risk of their idiosyncratic income fluctuations with the rest of the world. A country's sudden loss of access to international capital markets is ruled out by assumption. Moreover, while RBC models have been successful at accounting for several features of regular business cycles in small open economies (see Mendoza (1991a) and (1994) and Correia, Neves

${ }^{1}$ Calvo and Reinhart (1999) and Milesi-Ferretti and Razin (2000) document in detail the reversals of capital inflows and the sharp contractions in economic activity associated with Sudden Stops. The document by the International Monetary Fund (1999) documents the collapses in equity prices and the increase in their volatility. Mendoza (2002) and Parsley (2000) show evidence of sharp changes in the relative price of nontradables for Hong Kong, Korea and Mexico. 
and Rebelo (1995)), they cannot account for the large magnitude of the collapses in output, consumption and investment, and the large adjustment in relative prices, observed during a Sudden Stop. Similarly, general-equilibrium asset pricing models have difficulties in accounting for the observed large asset price declines and for the contagion of asset price volatility across countries.

The pressing need to gain a better understanding of the Sudden Stops phenomenon has led to the development of an active research program seeking to build models that can deliver predictions consistent with this phenomenon (see, for example, the November, 1996 and June, 2000 symposia issues of the Journal of International Economics or the NBER volumes edited by Edwards (2000), Krugman (2000a) and Frankel and Edwards (2002)). The initial step of this research program was to recognize that an analytical framework that aims to explain the empirical regularities of emerging markets crises requires a reconsideration of the conventional approach to model international capital markets as a perfect mechanism for consumption smoothing, risk sharing and credit allocation (see Calvo and Mendoza (1996)). Moreover, since international capital markets across industrial countries are much less volatile than emerging markets, it was also important to identify at the outset factors that may explain why emerging capital markets are significantly more prone to fail than the capital markets of industrial countries (see Krugman (2000b) and Calvo and Mendoza (2000a) and (2000b)). Thus, the common starting point of much of the literature on emerging markets crises has been to model international capital markets as subject to a variety of financial-market imperfections and to attribute these imperfections to various forms of informational frictions that are more pervasive in emerging markets than in industrial-country capital markets. Most of the literature focuses on theoretical partial-equilibrium models that yield qualitative results consistent with some of the 
features that define a Sudden Stop. Very little is known yet about whether these models provide a reasonable quantitative account of a typical emerging markets crisis.

The main objective of this paper is to analyze a framework that aims to integrate some of the financial-frictions channels proposed in the recent literature on emerging markets crises with an equilibrium business cycle model for small open economies. The emphasis is on developing methods for deriving the quantitative implications of the proposed framework and on using these quantitative methods to learn about the strengths and weaknesses of financial-frictions theories of the Sudden Stop phenomenon. The paper also provides a short survey of the recent literature with the aim of highlighting the differences between the alternative financial transmission mechanisms that have been proposed.

The paper is organized as follows. Section 2 surveys the recent literature on creditfrictions models of Sudden Stops. Section 3 proposes a basic macroeconomic framework for integrating financial frictions into RBC models of the small open economy. Section 4 reviews four applications of this framework. Section 5 concludes and discusses several venues for further research.

\section{Varieties of Credit Frictions}

A large portion of the recent literature on emerging markets crises proposes financial transmission mechanisms that can be roughly divided into two categories. First, a group of studies explore financial transmission mechanisms driven by a debtor's ability to pay. In these models, debtors may be willing to repay their debts but their ability to do so is threatened by the realization of "bad" states of nature. Creditors aim to cover their exposure to this default risk by imposing lending conditions on borrowers (usually in the form of collateral or liquidity requirements) or by choosing to incur monitoring costs to assess a borrower's claim not to be 
able to repay. The second category emphasizes a debtor's willingness to pay. In these models, debtors decide optimally to renege on their debts when the expected lifetime payoff of defaulting, net of any default penalty, exceeds the expected lifetime payoff of repaying.

Most of the work published to date in both of the above categories is theoretical in nature and is based in part on the related literature on financial frictions and contract theory in Macroeconomics, International Macroeconomics and Finance produced in the last two decades. Note also that the two-category classification is a natural way or organizing the literature but it hides the fact that several of the models that have been proposed combine elements of ability and willingness to pay (costly monitoring models, for example, have elements of both ability to pay and willingness to pay since they deal with the inability of a lender to tell if a defaulting borrower is unable to pay or unwilling to pay without incurring the monitoring cost).

\subsection{Ability-to-pay Models}

Models driven by ability to pay generally specify explicit constraints linking a country's ability to acquire debt to the dynamics of income and prices or to various forms of collateral. The motivation for these constraints comes from the lenders' interest in managing default risk and from informational asymmetries between borrowers and lenders.

Calvo (1998) presents a very clear characterization of an ability-to-pay framework as a mechanism for explaining Sudden Stops. He considers a perfect-foresight, three-period small open economy with traded and nontraded goods that are separable in utility. An endowment of traded goods is received only in the last period and production of nontraded goods is planned at date 0 , using a linear technology in which tradables enter as an input and output is obtained a period later. Thus, at date 0 firms borrow to import tradables to use as input in nontradables production acting on a perceived relative price for nontradables sold at date 1 . At date 1, 
tradables and nontradables are consumed, producers' debt is due and new debt is contracted to import tradables for consumption. At date 2, tradables are consumed and debt is paid. In this economy, the Pareto optimal competitive equilibrium free of credit-market imperfections obtains when the date- 0 perceived nontradables relative price equals the actual date- 1 equilibrium price. Firms are always able to repay their debt.

The outcome differs sharply if there is a temporary shock to the country's ability to access capital markets in period 1, once production plans are implemented, and there are fixed bankruptcy costs that increase the real cost of servicing debt at date 2 . In this case, the competitive equilibrium yields two mutually-consistent outcomes. On one hand, there is bankruptcy, that is firms become unable to repay their debt. On the other hand, the equilibrium relative price of nontradables is lower than the perceived date-0 price. This occurs because bankruptcy costs lower the permanent income of the economy and thus the consumption of tradables at dates 1 and 2 . The decline in tradables consumption at date 1 induces a fall in the marginal rate of substitution between nontradables and tradables, and hence in the equilibrium relative price of nontradables. This price decline renders firms bankrupt because they made zero-profits production plans at the higher Pareto-optimal price perceived at date 0 .

The shock to credit market access and the bankruptcy costs are both central to Calvo's story. If firms cannot roll over their debt temporarily but bankruptcy does not entail costs, households could borrow to cover the firms' obligations (assuming unlimited-liability firms) and the Pareto-optimal equilibrium would prevail. This model is highly stylized but its main prediction (i.e., that large, unexpected relative price changes induced by credit frictions can trigger Sudden Stops) is robust to several modifications in terms of the life horizon, the form of the utility function, and the tradables endowment process. Mendoza (2002), for example, 
considers an RBC-like, two-sector model that delivers similar findings by introducing a borrowing constraint set in terms of a fraction of gross domestic product in units of tradables (this model is discussed in Section 4.1 below).

Ability-to-pay models of Sudden Stops based on collateral constraints typically emphasize constraints analogous to the well-known collateral constraint studied by Kiyotaki and Moore (1997). In these models, foreign debt is constrained not to exceed the discounted liquidation value of the capital stock one period into the future. Models of this class include those of Izquierdo (2000), Edison, Luangaram and Miller (2000) and Paasche (2001).

Izquierdo (2000) and Edison, Luangaram and Miller (2000) use Kiyotaki-Moore (KM) constraints to study how this credit-market friction could explain the large real effects observed during the Tequila and East Asian crises. They find that the response of credit-constrained economies to financial shocks, such as a fall of the exchange rate, can greatly amplify the real effects of these shocks and lead to systemic financial collapse. Izquierdo argues that these magnification effects lead to an asymmetric response relative to what is observed when positive shocks hit the economy, and shows evidence of asymmetric responses in a panel for Latin America. Paasche (2001) examines the extent to which a crisis in a country can spread to another seemingly unrelated country, when two small open economies that face K-M constraints export differentiated goods to a large country. An adverse, temporary terms-of-trade shock triggered by a productivity shock to one of the small economies causes large capital outflows and a rapid deterioration in the current account of the other small economy.

Other studies make use of collateral constraints that differ from the K-M constraint. These include Caballero and Krishnamurthy (2001), Auernhaimer and Garcia-Saltos (2000), Schneider and Tornell (1999), Christiano, Guts and Roldos (2001) and Mendoza and Smith 
(2001). A common feature of these studies is that they produce collateral-based financial transmission mechanisms that magnify the real effects of macroeconomic shocks. Caballero and Krishnamurty focus on differences across domestic industries in their ability to offer "useful" collateral to international lenders. Auernheimer and Garcia-Saltos link the cost of borrowing explicitly to the market value of the capital stock, as a form of implicit collateral. Schneider and Tornell study the interaction of collateral constraints that comprise land, a fraction of risky capital and a fraction of bonds, with government bailouts guarantees. Christiano et al. and Mendoza and Smith study collateral constraints that depend on the current liquidation value of assets, a form of collateral constraint often referred to as a margin requirement (see Aiyagari and Gertler (1999)).

Quantitative applications of ability-to-pay models in an RBC setting are rare (some examples are presented in Section 4), but there are numerical results for some of the models cited above for perfect-foresight experiments. Paasche (2001) and Auernheimer and Garcia Saltos (2000) study simulations of their models to explore the magnitude of the real effects they can produce in response to unanticipated shocks. Christiano, Gust and Roldos (2001) and Cespedes, Chang and Velasco (2001) develop quantitative models aimed at answering policy questions. Christiano et al. study how a change in the domestic interest rate affects output when a small open economy runs into a binding collateral constraint by which debt is constrained not to exceed a fraction of the current value of domestic assets. Firms require two types of working capital: domestic currency to hire domestic inputs and foreign currency to finance imports of an intermediate input. Borrowers and lenders do not anticipate the possibility of the suddenlybinding borrowing constraint hitting the economy, so the constraint emerges as an unanticipated shock to a perfect-foresight equilibrium as in the experiments of Paasche and Auernheimer and 
Garcia-Saltos. In this setting, an interest rate cut can produce a fall in the value of domestic assets via a nominal exchange-rate depreciation, which in turn reduces imports of the foreign input. If the foreign input is not very substitutable for domestically-produced inputs, a contraction in output follows. Depending on how labor enters in production and how it responds to the interest rate cut, however, the model can also predict that an expansion could follow from the interest rate cut.

Cespedes et al. (2001) consider a setup of monitoring costs analogous to the BernankeGertler financial accelerator model to study the relation among exchange rate regimes, balancesheet effects, nominal rigidities and macroeconomic outcomes. In their model, balance-sheet effects magnify the adverse real effects of a foreign shock that triggers a real devaluation of the currency. However, these real effects are always larger with a fixed exchange rate than with a flexible one because the former does not help the economy cope with nominal rigidities and makes no difference for the nature of the Bernanke-Gertler external financing premium.

From the perspective of developing an equilibrium business cycle approach to explain Sudden Stops, the above literature on ability-to-pay models faces two challenges. One is that in the majority of the existing models borrowing constraints are always binding along an equilibrium path. This rules out equilibrium dynamics in which one can observe large reversals of the current account triggered by a switch from a state of nature in which the constraint did not bind to one in which it does (as implicit in Calvo's (1998) setup). The second shortcoming is that most models deal with perfect-foresight experiments in which the credit constraint arrives as an unexpected shock. Hence, economic agents are not given the opportunity to adapt their optimal plans to the possibility of being suddenly unable to access international capital markets. As shown later, optimal plans differ sharply even if the probability of this event is negligible. 


\subsection{Willingness-to-pay Models}

The literature on international debt that emphasizes willingness to pay was very active in the aftermath of the developing-country debt crisis of the 1980s, and is now going through a renaissance motivated both by the emerging markets crises and the recent developments in closed-economy finance theory. The premise in this literature is that credit markets are intrinsically fragile because, in the absence of efficient mechanisms for committing debtors to fulfill their obligations, debtors optimally choose to default whenever the lifetime payoff of doing so exceeds the payoff of continuing in a credit relationship. However, the implications of this incentive-compatibility or participation constraint vary depending on the structure of the economic environment on which it is imposed.

Consider first the classic article on sovereign default by Eaton and Gersovitz (1981) in which a sovereign debtor in default faces permanent exclusion of international capital markets (i.e., consumption must be set at the same level of the economy's income endowment each period). Eaton and Gerosvitz set this debtor in a global credit market with fully-informed, riskneutral lenders that are willing to lend at a default-risk premium that equates the expected return on risky sovereign debt with that of a riskless asset (up to a maximum lending ceiling). The default risk premium is an endogenous outcome that reflects the probability that borrowers find themselves in states of nature at which it is optimal to default because the participation constraint fails. Default is observed at equilibrium when these states occur.

Atkeson (1991) considers a model in which the participation constraint interacts with a moral hazard problem in a contracting environment in which repayment schedules are contingent on output realizations. In particular, lenders cannot observe whether borrowed funds are used for investment or consumption. The optimal contract features capital outflows from the borrowing 
country as a solution to the moral hazard problem.

The above studies assume that countries cannot enter into other financial agreements after they renege on their debts, and thus that financial autarky is a credible threat. However, a key lingering question facing this literature is whether creditors really posses the ability to penalize debtors in this way. Bulow and Rogoff (1989) show that a sufficient condition for the reputational mechanism implicit in satisfying the participation constraint to fail to enforce debt repayments is that countries in default may have access to a rich set of deposit contracts with foreign creditors. Thus, a country that has large expected repayments due can default and then save the resources at stake in deposit contracts, thereby enjoying a higher level of consumption (and utility) thereafter. Rational lenders foresee this outcome and so international borrowing cannot be sustained in equilibrium.

The Bulow-Rogoff paradox has been addressed in different ways. Bulow and Rogoff (1989) provided an answer based on the notion that lenders may be able to impose direct trade sanctions on defaulting borrowers. More recently, Kletzer and Wright (2000) proposed an environment in which both lenders and borrowers lack capacity of commitment. This limits the set of deposit contracts that defaulting economies have access to if they default. The authors show how the two-side commitment problem they study can restore sustainable intertemporal exchange through reputation by constructing a renegotiation-proof equilibrium where payments are state contingent and contracts are incentive-compatible for both parties. Finally, Wright (2001) looks at how a country's concern for reputation can work to enforce repayment when there are also reputational incentives on the side of lenders that lead them to tacitly collude in punishing a country in default. If syndicated lending is allowed, banks collude to punish countries in default so as to preserve their own reputation for cooperation. 
Quantitative applications of willingness-to-pay models applied to the study of Sudden Stops are as rare as those of the ability-to-pay models. Most of the literature focuses on examining theoretically the strategic interaction of borrowers and lenders and the properties of the resulting incentive-compatible contract, although some quantitative applications of models in this class do exist. Perri and Kehoe (2001) study business cycle co-movements across industrial countries in a two-country model in which each country is required to satisfy its participation constraint in each state of nature, following the closed-economy analysis of Kehoe and Levine (1993) and Kocherlakota (1996). From the perspective of emerging markets crises, however, this modeling approach has difficulties in accounting for defaults because the need to satisfy the participation constraints at all times rules them out at equilibrium. ${ }^{2}$ Also, depending on preference and technology parameters and on the stochastic structure of the shocks hitting the economy, these models can predict that the incentives for default tend to be stronger for countries that are in good states of nature or that experience less macroeconomic volatility.

Hamann (2002) studies the quantitative implications of the Eaton-Gersovitz framework and he does explore its ability to account for some features of emerging markets crises, albeit in the context of a pure exchange economy. He shows how increased persistence or variance in the endowment income process can reproduce some features of a Sudden Stop in which borrowing constraints are tightened and the default risk premium is increased. To do so, he exploits the feedback between these changes in the income process, the equilibrium probability of default, and the optimizing behavior of the risk-neutral lenders assumed in the Eaton-Gersovitz model.

In summary, the growing literature studying emerging markets crises from the abilityand willingness-to-pay approaches has made important contributions to our understanding of the

\footnotetext{
${ }^{2}$ In these models there can be states of nature in which borrowers and lenders agree to a zero payment but always as part of the contract that enforces the incentive compatibility constraint.
} 
process that drives Sudden Stops. Related studies that have examined Sudden Stops as the outcome of self-fulfilling expectations, informational cascades, or working capital distortions (see, for example, Aghion, Bacchetta, and Banerjee, (2000) Calvo (2000), Chari and Kehoe (2002), Cole and Kehoe (1996), Reif (2001), Neumeyer and Perri (2001) and Oviedo (2002)) have also made valuable contributions. Yet, little is still known about the quantitative implications of these models in an equilibrium business cycle setting, and about whether the financial transmission channels they propose offer a quantitatively plausible account of the Sudden Stop phenomenon. In the next two sections we describe an equilibrium business cycle framework with financial frictions that tries to make some progress in this regard.

\section{Real Business Cycles in Small Open Economies with Financial Frictions}

This Section proposes a modification of the standard RBC framework for the small open economy that introduces financial frictions. The standard small-open-economy RBC model (as in Mendoza (1991a)) features a representative infinitely-lived household, a representative firm operating a neoclassical production technology subject to random productivity disturbances and facing capital-adjustment costs, and an international credit market of one-period, non-contingent bonds. In this model, markets of contingent claims are incomplete but the credit market is perfect (i.e., the small open economy can borrow or lend at the world-determined real interest rate any amount that is consistent with the household's no-Ponzi-game condition).

In addition to the above assumptions, small open economy $\mathrm{RBC}$ models typically require extra assumptions regarding the nature of intertemporal preferences or international bond markets in order to support a well-defined stochastic stationary state from which to compute business cycle moments that can be compared to moments in the data. It is well-known that deterministic small-open-economy models, with standard time-separable preferences featuring 
an exogenous rate of time preference and the standard global credit market with an exogenous interest rate, yield either explosive dynamics (if the rate of time preference and the interest rate differ) or stationary equilibria that depend on initial conditions (if the rate of time preference and the interest rate are identical). Obstfeld (1981) showed how preferences with an endogenous rate of time preference could be used to obtain well-defined foreign asset accumulation dynamics (with a unique steady state independent of initial conditions) in a perfect foresight small-openeconomy model. Similarly, the RBC model in Mendoza (1991a) used preferences with endogenous discounting in order to obtain a well-defined limiting distribution of foreign assets.

In stochastic environments, intertemporal preferences with an endogenous rate of time preference take the form of Epstein's (1983) Stationary Cardinal Utility (SCU) function:

$$
E_{0}\left[\sum_{t=0}^{\infty} \exp \left\{-\sum_{\tau=0}^{t-1} v\left(c_{\tau}\right)\right\} u\left(c_{t}\right)\right]
$$

In this expression, $u($.$) is a standard twice-continuously-differentiable and concave utility$ function and $v($.$) is the time preference function, which is assumed to be increasing, concave and$ twice-continuously-differentiable. SCU also imposes restrictions linking the two functions that can be interpreted as setting an upper bound on the elasticity of the rate of time preference with respect to the argument of utility. These restrictions imply that the impatience effect, by which changes in date-t consumption alter the rate at which all future utility flows are discounted, must be "small" (in the sense that the rate of time preference, $\exp (v()$.$) , is increasing in the argument$ of utility but maintaining the condition that $u_{1}(\cdot) \exp (-v(\cdot))$ is non-increasing). This is necessary in order to ensure that consumption at every date is a normal good and that the model supports a well-defined unique, invariant limiting distribution (see Epstein (1983)).

Endogenous discounting is not the only method used to obtain a unique, invariant 
limiting distribution in stochastic small-open-economy models. Other methods explored in the literature include finitely-lived households (i.e., Blanchard preferences), transactions costs in foreign assets, and ad-hoc interest rate functions that link the rate of interest to the stock of foreign debt. Moreover, since the small-open-economy RBC model has only one non-statecontingent asset and hence features non-insurable, idiosyncratic risk, the model is in the class of incomplete-markets models for which precautionary savings can yield a well-defined stochastic steady state even with an exogenous discount factor (as long as the rate of time preference is set higher than the world interest rate, see Chapter 14 in Ljungqvist and Sargent (2000)).

Some of these alternative methods can yield similar results as the endogenous discount factor in particular log-linear quantitative applications (see Schmittt-Grohe and Uribe (2001)), but this equivalence is unlikely to hold in models that aim to capture a Sudden Stop's large, nonlinear adjustments. In addition, Epstein's utility function is the only formulation consistent with three standard features of RBC models: economic agents are infinitely-lived, the rate of time preference and the rate of interest are equal in the long run, and the long-run foreign asset position is determined by the interaction of household preferences with the real interest rate and not by ad-hoc specifications of transactions-costs or interest-rate functions. Moreover, Epstein (1983) showed that SCU as a representation of a preference order requires weaker axioms of consumer theory than the ones required by time-separable utility with exogenous discounting.

In the context of models with financial frictions, preferences with endogenous discounting have the extra advantage that they allow for the possibility that credit constraints can remain binding at steady state. This is because a binding credit constraint drives a wedge between the intertemporal marginal rate of substitution in consumption and the rate of interest. In a stationary state with a binding credit constraint the rate of time preference adjusts 
endogenously to accommodate this wedge. In contrast, in models with an exogenous discount factor credit constraints never bind in the long run (if the exogenous rate of time preference is set greater or equal than the world interest rate) or must always bind at steady state (if the rate of time preference is fixed below the interest rate).

The recursive representation of the competitive equilibrium of the small-open-economy $\mathrm{RBC}$ model is characterized by optimal decision rules for the vector $y=[c, n, i]$ of control variables (where $c$ is consumption, $n$ is labor supply, and $i=k^{\prime}-k(1-\delta)$ is gross investment) and the vector $x^{\prime}=\left[k^{\prime}, b^{\prime}\right]$ of endogenous states (where $k^{\prime}$ is capital accumulation and $b^{\prime}$ is foreign asset accumulation) that solve the following dynamic-programming form of a planner's problem:

$$
\begin{aligned}
& V(k, b, e)=\max _{k^{\prime}, b^{\prime}, c, n}\left\{u(c, n)+\exp (-v(c, n)) E\left[V\left(k^{\prime}, b^{\prime}, e^{\prime}\right)\right]\right\} \\
& \text { s.t. } \quad c=e f(k, n)-k^{\prime}+k(1-\delta)-\varphi\left(k, k^{\prime}\right)-b^{\prime}+b R
\end{aligned}
$$

where $f($.$) is a neoclassical production function, \delta$ is the rate of depreciation of the capital stock, $\varphi$ is a convex capital-adjustment-cost function, $R$ is the world's gross real interest rate and $e$ is a productivity disturbance that follows a Markov process with a known transition probability matrix. The initial state of the system is given by the observed realization of $e$ and by the vector $x=[k, b]$, where $k$ is the initial capital stock and $b$ the initial net foreign asset position.

The above social planner's problem can be decentralized in standard fashion to establish the equivalence between the planner's problem and the competitive equilibrium of an economy in which households own the factors of production and rent them out to profit-maximizing firms. The prices and factor rental rates that support equilibrium allocations include the wage rate, $w$, the rental rate of capital, $r$, and the relative price of investment goods in terms of consumption goods, $q$ - which is not equal to 1 because of the capital-adjustment costs. The price vector that 
households and firms take as given is thus defined by $p=[w, r, q]$.

Consider now a modification of the above economic environment in which financial markets are imperfect. The first change to notice is that, since financial frictions distort the competitive equilibrium, it may be necessary to study the equilibria of these economies directly in decentralized form. Alternatively, it may be possible to construct a variant of a planning problem that captures the distortions induced by specific forms of financial-market imperfections on the competitive equilibrium (as in the applications studied in Section 4).

This paper focuses on financial frictions that reduce to functional constraints on the small open economy's ability to contract foreign debt of the following form:

$$
b^{\prime} \geq h\left(k^{\prime}, x, y, e, p\right)
$$

This state-contingent borrowing constraint is not formally derived as a feature of an optimal credit contract between the small open economy and its international creditors. However, the next section's review of four applications of this framework relates explicit forms of the borrowing constraint to existing results for optimal credit contracts or to observed practice in actual credit markets. The above specification is general enough to include a broad range of applications, including liquidity requirements, margin constraints, borrowing ceilings set to support debt repayment incentives, and collateral constraints set to the current liquidation value of assets. One exception is the Kiyotaki-Moore collateral constraint, which depends on future realizations of an element of $p$ (the next period's equity price). ${ }^{3}$

The appropriate planner's-problem representation of the borrowing constraint can be derived once explicit functional forms for the financial frictions affecting households and/or

\footnotetext{
${ }^{3}$ Despite this limitation, other collateral constraints that are included in $h$, like margin requirements, have similar asset-pricing implications as Kiyotaki-Moore constraints (see Mendoza and Smith (2001) for details).
} 
firms in the decentralized competitive equilibrium are defined. For example, the planner's borrowing constraint may represent a constraint limiting households' foreign debt not to exceed a fraction of factor income or firms' ability to leverage their debt on the value of their capital. Under particular assumptions, the competitive equilibria of economies with these constraints can be shown to be equivalent to that of a planning problem in which debt is limited not to exceed a fraction of output or a fraction of the market value of the capital stock. In general, however, whether such equivalence between competitive equilibria and a planner's problem exists needs to be examined case by case.

At this level of generality it is possible to extract some important properties of smallopen-economy RBC models that incorporate the above borrowing constraint:

(1) The borrowing constraint is "occasionally binding." Whether the constraint binds or not depends ultimately on the initial state $(x, e)$. Note that since the equilibrium is represented in recursive, social-planner's form, the optimal decision rules for $k$ ' and $y$ and the equilibrium pricing vector $p$ in the right-hand-side of (2) are also functions of $x$ and $e$.

(2) The dynamics of the borrowing constraint and equilibrium allocations and prices feature endogenous feedback effects. Knowledge that the constraint is a feature of the financial markets in which the small open economy participates, influences the optimal forwardlooking plans that economic agents formulate. As a result, it also influences the equilibrium dynamics of prices and allocations, which in turn determine whether the constraint binds or not. In particular, the agents' expectations that they may face future states in which the borrowing constraint can bind influences their decisions to accumulate assets today and thus the probability that the constraint can actually bind in the future.

(3) Suddenly-binding borrowing constraints can produce non-linear dynamics and country- 
specific risk premia. When the economy switches from a state in which the constraint does not bind to a state in which it binds, there are discrete jumps upward in the effective intertemporal relative price of current consumption and downward (upward) in the level of current (future) consumption. This follows from the household's consumption Euler equation, which takes the form:

$$
\lambda=E\left[\lambda^{\prime} R^{\prime}+\mu\right]
$$

where $\lambda$ is the lifetime marginal utility of consumption (i.e. the non-negative Lagrange multiplier on the resource constraint facing the planner) and $\mu$ is the non-negative Lagrange multiplier on the borrowing constraint. The increased effective real interest rate in the states in which the borrowing constraint binds represents an endogenous, country-specific risk premium on external financing.

(4) The borrowing constraint can depress asset prices and trigger Fisherian debt-deflation dynamics. As shown in the next Section, the higher effective interest rates implied by either a currently-binding or expected-future-binding borrowing constraint depresses current equity prices by increasing the discount rates relevant for discounting dividend streams in the valuation of assets. If the specification of $h($.$) links the borrowing$ constraint to asset prices, the adverse asset-pricing implications of the constraint add a feedback effect in the spirit of Fisher's debt deflation mechanism: an initial shock triggers the borrowing constraint, this leads to a decline in asset prices, which then leads to an even tighter borrowing constraint and thus a downward spiral on asset prices and access to foreign financing.

An important implication of these four properties is that the small-open-economy RBC framework with borrowing constraints is endowed with a self-adjustment mechanism that 
actually works to weaken the quantitative effects of financial frictions. That mechanism is the precautionary savings motive: Risk-averse agents respond to their non-insurable exposure to the risk of a binding borrowing limit, which adversely affects their consumption plans, by accumulating a buffer stock of assets. Precautionary savings can also distort portfolio choice in models in which foreign assets co-exist with other vehicles of saving such as physical capital or equity. As mentioned earlier, this precautionary-savings effect is already present in the frictionless small-open-economy RBC model because the non-contingent international bond cannot fully insure agents against country-specific idiosyncratic income shocks. The effect is stronger in the presence of borrowing constraints, however, because agents in the frictionless model could rely on a perfect international credit market to support optimal consumption plans and they have the option of using domestic investment as an alternative savings vehicle. ${ }^{4}$

Dealing with the precautionary savings motive is an important unfinished task for the literature on financial frictions in small open economies. The majority of models of the Sudden Stops phenomenon abstract from it by assuming perfect foresight or by focusing on experiments in which the financial frictions are a negative unanticipated shock to the economic environment. Thus, in these experiments economic agents are not allowed to condition their behavior on the possibility of the occurrence of states of nature in which they are forced out of international capital markets. While this assumption has proven useful for obtaining insightful analytical results, it is important to relax it in order to integrate financial frictions into equilibrium business cycle models for small open economies.

In principle, precautionary savings may seem reason to cast doubt on the potential of models with financial frictions to offer a quantitatively significant account of the empirical

\footnotetext{
${ }^{4}$ Mendoza (1991b) shows that, in the standard small open economy RBC model, agents can adjust investment and suffer a negligible welfare loss even if they are forced out of the world
} 
regularities of emerging markets crises. Yet, precautionary savings are in fact a key property of these models that enables them to mimic an observed feature of the data: Sudden Stops are dramatic but relatively rare. The cyclical downturns experienced in countries that have suffered Sudden Stops were large, but they were also abnormally large relative to those countries' regular business cycles (see Mendoza (2002) and Calvo and Reinhart (2001)). Thus, it seems natural to think of designing equilibrium business cycle models that aim to explain Sudden Stops by nesting these dramatic, rare events within more a regular business cycle pattern. ${ }^{5}$ It is undesirable to follow an approach with two disconnected theories of economic fluctuations for emerging economies, one for Sudden Stops and one for tranquil times, in which key assumptions regarding the ability of agents to condition their behavior on the possibility of the economy suddenly losing access to world capital markets in the future are emphasized in the former but dismissed in the latter.

\section{Applications}

This Section of the paper reviews four applications of the general framework proposed in Section 3 that aim to capture financial frictions similar to those emphasized in the literature on emerging-markets crises. The first application considers a liquidity requirement that at equilibrium represents a constraint on the debt-to-output ratio of a two-sector economy (this model is borrowed from Mendoza (2002)). The liquidity requirement incorporates the phenomenon known as "liability dollarization:" foreign debt is denominated in units of tradable goods but serviced in part with income generated in the nontradables sector, and hence large

credit market altogether.

${ }^{5}$ If Sudden Stops are nested as rare events within regular business cycles, the RBC approach to compare statistical moments of detrended data with the moments of the ergodic distribution of business cycle models is unlikely to be useful for studying Sudden Stops. The next Section discusses one alternative approach that can be followed to study the models' ability to explain Sudden Stops. 
swings in the relative price of nontradables, or in the real exchange rate, can trigger binding borrowing constraints and sudden current account reversals. The second application reviews the asset-pricing model of Mendoza and Smith (2001). This model incorporates two financial frictions. First, a friction in the international credit market analogous to a margin requirement by which a fraction of the value of equity holdings must be offered as collateral for foreign debt. Second, informational frictions in the equity market that result in transactions costs in trading the small open economy's equity for foreign securities firms. The third application looks at Arellano's (2002) analysis of borrowing constraints that enforce credit-market participation constraints in an environment with incomplete insurance markets. The fourth application considers a model with capital adjustment costs that features a collateral constraint similar to the margin requirement used in the asset-pricing model but in a setup with endogenous capital accumulation. Foreign creditors retain as collateral a fraction of the value of the economy's capital stock where this value is determined by Tobin's $q$.

4.1 Liquidity Requirements and Liability Dollarization in a Two-Sector Economy Consider a small open economy with two sectors, a tradable goods sector and a nontradable goods sector. The output of tradables is a stochastic endowment $\exp (\varepsilon) y^{T}$, where $\varepsilon$ is random variable that follows a Markov process. Non-tradable goods are produced using a CobbDouglas production function $F(k, n)=\exp (\varepsilon) A k^{1-\alpha} n^{\alpha}$, where $A$ is a productivity scaling factor, $n$ is variable labor input, $k$ is the time-invariant capital stock, and $0<\alpha<1$ is the output share of labor income. The production of nontradables is subject to productivity shocks, which are assumed to be perfectly correlated with the shocks to the tradables endowment for simplicity.

Private consumption of tradables $\left(c^{T}\right)$ and nontradables $\left(c^{N}\right)$ is aggregated into a composite good using a standard constant-elasticity-of-substitution (CES) aggregator 
$c=\left[\omega\left(c^{T}\right)^{-\eta}+(1-\omega)\left(c^{N}\right)^{-\eta}\right]^{-\frac{1}{\eta}}$, where $0<\omega<1$ and $\eta>-1$ are the standard CES parameters $\left(1 /(1+\eta)\right.$ is the elasticity of substitution between $c^{T}$ and $\left.c^{N}\right)$. The argument of utility adopts the Greenwood-Hercowitz-Huffman specification, $c-\frac{n^{\delta}}{\delta}$ (with $\left.\delta>1\right)$, which makes the marginal rate of substitution between $n$ and $c$ independent of the latter and sets the wage elasticity of labor supply equal to $1 /(\delta-1)$.

The economy has access to a global credit market of one-period bonds $(b)$ in which it acts as a small price-taker. The world gross real interest rate $\exp \left(\varepsilon^{R}\right) R$ is subject to random shocks $\varepsilon^{R}$ which also follow a Markov process.

The government of the small open economy levies a consumption tax $\tau$ that is uniform across goods. This tax is intended to capture some of the distortions that can result from fiscal, monetary and exchange-rate policies in models in which money enters as an argument of the utility function or as a means to economize transactions costs (see Mendoza (2001) and Mendoza and Uribe (2001) for details). Private agents perceive tax policy as uncertain and thus attach positive probability to scenarios in which the economy can switch from low to high-tax regimes and vice versa. Hence, the consumption tax is modeled as a standard regime-switching, asymmetric Markov process. The government also maintains a constant level of unproductive purchases of nontradables financed by a time-invariant lump-sum tax $T^{N}$. This ensures that the dynamics of the relative price of nontradables $\left(p^{N}\right)$ are driven only by changes in private-sector supply and demand choices and not by endogenous changes in government purchases due to fluctuations in tax revenue. Fluctuations in tax revenue result in fluctuations of unproductive government purchases of tradable goods around a "trend" level financed also by a time-invariant 
lump-sum tax $T^{T}$. This assumption introduces the Calvo-Drazen fiscal-induced wealth effects that Calvo and Drazen (1988) and Mendoza and Uribe (2001) found critical for explaining key features of economic fluctuations in developing countries exposed to the risk of uncertain duration of government policy.

The global credit market is imperfect. In particular, the small open economy must satisfy a liquidity requirement by which a fraction $\phi$ of current expenditures, tax and debt service obligations must be paid out of current income which is valued in the same units as debt contracts are written in (i.e., in units of tradable goods):

$$
w_{t} n_{t}+\pi_{t} \geq \phi\left[\left(1+\tau_{t}\right)\left(c_{t}^{T}+p_{t}^{N} c_{t}^{N}\right)-\exp \left(\varepsilon_{t}^{R}\right) R b_{t}+T_{t}^{T}+p_{t}^{N} T_{t}^{N}\right]
$$

Here, $w$ is the wage rate and $\pi$ are rents on the time invariant capital stock paid by firms producing nontradables. This liquidity requirement and the household's budget constraint imply that the economy faces a borrowing constraint that limits debt not to exceed a fraction $(1-\phi) / \phi$ of household income in units of tradables:

$$
b_{t+1} \geq-\frac{1-\phi}{\phi}\left[w_{t} n_{t}+\pi_{t}\right]
$$

An intuitive motivation for this liquidity requirement is that it helps creditors to manage default risk because it is an ability-to-pay criterion that reduces the likelihood of observing situations in which the current income of borrowers falls short of what is needed to pay for existing debts. This is accomplished by limiting the margin by which the borrowers' current obligations can exceed their current income (i.e., by forcing borrowers to maintain a certain level of "liquidity"). Borrowing constraints of this form are widely used by lenders in determining maximum loan amounts and setting borrowers' qualification criteria, particularly in mortgage loans and consumer debt contracts. 
Despite its empirical appeal, the liquidity requirement is not modeled here as the outcome of an optimal contract between lenders and borrowers. It is not optimal from the ability-to-pay standpoint because it does not fully ensure that debtors will have enough current income to repay their debts in every state of nature. To do so, $\phi$ would have to be contingent on $b_{t}$ and on the stochastic processes governing the exogenous shocks. It is not optimal from the willingness-topay perspective because it does not ensure that borrowers will satisfy their participation constraint. These caveats imply that the use of the liquidity requirement is supported by two implicit participation assumptions. First, contract-enforcing institutions are such that borrowers are committed to honor debt contracts that feature the liquidity requirement even if they find themselves in states of nature in which it is not incentive-compatible for them to do so. Second, debt contracts with the liquidity requirement also commit lenders to lend even if the borrowers' ability to repay out of current income in all future states is not guaranteed (i.e., debtors can always borrow at date $t$ if they satisfy the liquidity requirement, even if at $t+l$ there are some states of nature in which their income net of current expenditures and taxes is lower than debt service obligations).

The borrowing constraint in (6) can be incorporated into a planner's problem that yields a solution equivalent to the model's competitive equilibrium. Since factors earn their marginal products and factor payments exhaust output, the borrowing constraint in the planner's problem adopts the form of a constraint that limits debt not to exceed the fraction (1- $\phi) / \phi$ of GDP valued at tradables goods prices. Defining $\psi \equiv\left(\varepsilon, \varepsilon^{R}, \tau\right)$ as the triple of observed realizations of the exogenous shocks and adopting explicit functional forms for the period utility and time preference functions, the planner's problem in dynamic programming form is the following: 


$$
V(b, \psi)=\max _{b^{\prime}}\left\{\frac{\left[c-\frac{n^{\delta}}{\delta}\right]^{1-\sigma}-1}{1-\sigma}+\exp \left(-\beta\left[\operatorname{Ln}\left(1+c-\frac{n^{\delta}}{\delta}\right)\right]\right) E\left[V\left(b^{\prime}, \psi^{\prime}\right)\right]\right\}
$$

subject to:

$$
\begin{gathered}
(1+\tau) \hat{c}^{T}+\tau \hat{p}^{N} \hat{c}^{N}=\exp \left(\varepsilon^{T}\right) y^{T}-b^{\prime}+b \exp \left(\varepsilon^{R}\right) R-T^{T} \\
\hat{c}^{N}=\exp \left(\varepsilon^{N}\right) F(k, \hat{n})-g^{N} \\
b^{\prime} \geq-\left(\frac{1-\varphi}{\varphi}\right)\left(\exp \left(\varepsilon^{T}\right) y^{T}+\hat{p}^{N} \exp \left(\varepsilon^{N}\right) F(k, \hat{n})\right)
\end{gathered}
$$

Period utility is a standard constant-relative-risk-aversion utility function, with $\sigma$ as the coefficient of relative risk aversion. The time preference function is logarithmic and $\beta$ represents the elasticity of the rate of time preference with respect to $1+c-\frac{n_{t}^{\delta}}{\delta}$. The variables in "hats" represent solutions of a system of five nonlinear simultaneous equations in the five unknowns $\left[\hat{c}, \hat{c}^{T}, \hat{c}^{N}, \hat{n}, \hat{p}^{N}\right]$ that satisfy a subset of the competitive equilibrium conditions for each coordinate $\left(b, b^{\prime}, \psi\right)$ in the state space. If the liquidity constraint (10) is not binding, the five equations are: (i) the equilibrium condition equating the marginal rate of substitution between $c^{T}$ and $c^{N}$ with $p^{N}$, (ii) the equilibrium condition equating the marginal rate of substitution between $n$ and $c$ with the effective real wage (i.e., the post-tax marginal product of labor in units of tradables, $w /(1+\tau) p^{c}$, where $p^{c}$ is the CES relative price index of $c$ in units of tradables, which is itself a monotonic, increasing function of $p^{N}$ ), (iii) the market-clearing condition in the tradable goods market (eq. (8)), (iv) the market-clearing condition in the nontradable goods market (eq. (9)), and (v) the definition of the CES composite good $c$. If the liquidity constraint is binding, (10) holds with equality and replaces the labor-consumption optimality condition. 
The Bellman equation in (7) can be solved using a variety of well-known value or policy function iteration methods. One important caveat, however, is that policy-function-iteration methods based on linear interpolations and solution methods that use either approximately-linear or continuously-differentiable policy functions may perform poorly because of the nonlinearities or kinks in the decision rule for $b_{t+1}$ implied by the occasionally-binding borrowing constraint. These kinks do not extend to the value function, which remains continuously differentiable and concave.

The transmission mechanism that drives economic fluctuations in this model combines features of RBC and policy uncertainty models, with the credit-channel mechanism induced by the liquidity requirement. If the liquidity requirement never binds, the shocks to productivity and the world interest rate drive business cycles through the channels examined in the RBC literature for small open economies (see Mendoza (1991a) and (1995)). Tax shocks add to these channels through the wealth and substitution effects highlighted in the studies on uncertain duration of economic policies by Calvo and Drazen (1998) and Mendoza and Uribe (2001). Given a low tax at date $t$, the conditional expected tax for $t+l$ is higher than the tax observed at $t$. This triggers an intertemporal substitution effect: prices are relatively low at $t$ and hence agents substitute consumption intertemporally in favor of current consumption. Under uncertainty and in the presence of non-insurable income effects, due to the incompleteness of financial markets, there is also a state-contingent wealth effect. Each period that low taxes prevail, households benefit from the implicit lower level of government absorption, and this gain is added to their permanent income. This effect favors an increasing consumption path for the duration of the low-tax regime, followed by a collapse in consumption when a reversal of the tax cut takes place. The above intuition for the effects of policy uncertainty applies fully in partial 
equilibrium. In general equilibrium, a shift from a low to a high tax can also induce a decline in the output of nontradables, labor allocation, and relative price of nontradables. For the price of nontradables to fall, the reduction in demand for nontradables induced by the above-mentioned wealth and intertemporal substitution effects, must exceed the reduction in supply. In turn, for the supply of nontradables to fall in equilibrium, it must be the case that the combined effect of the reduction in the demand for labor (resulting from the reduced value of the marginal product of labor in the nontradables sector as $p^{N}$ falls) and the negative effect of the tax hike on labor supply, dominates the positive effect on labor supply resulting from the decline in $p^{C}$ (which is caused by the fall in the relative price of nontradables).

The credit channel of the liquidity requirement modifies the model's business cycle transmission mechanism by introducing the following effects in states of nature in which the credit constraint binds:

(a) The effective real interest rate faced by the small open economy increases because the binding borrowing constraint forces households to reduce consumption relative to the case with perfect credit markets. Hence, the collapse in aggregate consumption and in the demand for tradables and nontradables associated with adverse real and/or policy shocks is magnified when the economy's response to these shocks triggers the borrowing limit.

(b) The effective marginal reward to labor supply increases because the extra unit of labor enhances the household's ability to borrow. This moderates the negative effects of adverse tax and productivity shocks on labor supply.

(c) Consumption, saving, and net foreign asset accumulation (and hence the current account) exhibit intertemporal distortions that depend on the combined dynamic effects of (a) and (b) in general equilibrium. This is because the effective intertemporal relative price of aggregate 
consumption is the consumption-based real interest rate, $\exp \left(\varepsilon_{t}^{R}\right) R\left[p_{t}^{C}\left(1+\tau_{t}\right) / p_{t+1}^{C}\left(1+\tau_{t+1}\right)\right]$, which depends on the inverse of the rate of change of the relative price of consumption (which is determined by the change in the relative price of nontradables).

As a result of the above effects, households face an implicit risk premium in the use of foreign debt vis-a-vis their own saving in their efforts to smooth consumption that is analogous to the external financing premium faced by firms in models of Sudden Stops based on the Bernanke-Gertler financial accelerator. The differences are in that in the model proposed here the equilibrium risk premium is determined endogenously and is influenced by the risk-averse nature of the households' preferences and the economy's non-insurable aggregate risk. In contrast, in open-economy extensions of the Bernanke-Gertler framework the functional form representing the external financing premium in general equilibrium is identical to the partialequilibrium solution of a costly-monitoring contracting problem under risk neutrality and without aggregate risk.

Mendoza (2002) calibrates the liquidity requirements model to Mexican data and produces numerical simulations to examine the effects of the borrowing constraint on macroeconomic dynamics and welfare. The calibration parameters are reproduced in Table 1.

Figure 4 plots the ergodic distributions of foreign bond holdings with and without the liquidity requirement. The key business-cycle statistical moments of the model's endogenous variables computed using each of the ergodic distributions are listed in Table 2. Despite the marked differences between the two limiting distributions and the first moments, the majority of the standard deviations, GDP correlations and first-order autocorrelations show negligible differences across the economies with and without the borrowing constraint (except for those pertaining to foreign assets and net exports, which the Figure clearly predicts should change 
dramatically). Thus, in general the presence of the liquidity requirement does not alter the longrun business cycle features of the economy. As argued earlier, this is an important feature of models that aim to explain the Sudden Stops as rare events nested within a setup in which "regular" business cycles are more common. But, can the model replicate a Sudden Stop?

To answer this question, Figure 5 plots the impact effects of a change from a state of nature with high productivity, low world interest rate and low tax rate, or the "best" state, to the "worst state" with the opposite features on the model's endogenous variables as functions of the foreign bond position. The plots show that in the region in which the change from one state to the other triggers the borrowing constraint (i.e., where the foreign assets-output ratio rises as the foreign asset position falls) the model displays several Sudden Stop features. In particular, there is a large, sudden reversal in the current account, collapses in domestic production and consumption, and a sharp decline in the relative price of nontradables.

Mendoza (2002) elaborates on the economic forces that explain the markedly non-linear pattern of the impact effects by examining the model's optimality conditions and the distortions imposed on them by the multiplier on the borrowing constraint. Note that within the Sudden Stops region, output, consumption, and labor levels always drop and large current account reversals always occur, but the relative price of nontradables can fall sharply or increase sharply. This feature of the model results from the elastic labor supply that is assigned fully to the nontradables sector. Under these conditions, a Sudden Stop lowers the equilibrium allocations of both tradables and nontradables consumption, and hence the relative price of nontradables increases or falls depending on which of the two falls by more. If instead nontradables are modeled as being in inelastic supply when the Sudden Stop hits, as in Calvo's (1988) model, the real exchange rate would always fall. This could be done either by making labor supply inelastic 
or by assuming that labor is used to produce tradables. However, the fall in the relative price of nontradables could also be obtained under less extreme assumptions (allowing for elastic labor even going into both sectors), as long as the contraction in tradables consumption is larger than that in nontradables.

The effect of precautionary savings on the ergodic distribution of asset holdings in the economy with the liquidity requirement is evident in the ergodic distribution of the liquidityconstrained model (see Figure 4). Precautionary savings rule out observing states of nature with relatively high debt positions in the long run. In fact, there is only one foreign asset position with non-zero long-run probability and a binding borrowing constraint, which shows in the plot as the leftmost spike in the limiting distribution. Interestingly, the liquidity requirement imposes directly a constraint on the debt-to-GDP ratio but this yields optimizing behavior that shows in the ergodic distribution of foreign assets as equivalent to a long-run constraint on a maximum level of debt. The reason is again precautionary savings: households maintain a buffer stock of saving to avoid painful large downward adjustments in the argument of utility $c-\frac{n^{\delta}}{\delta}$ because of the curvature of the period utility function. In particular, they do not want to be exposed to the risk that this argument could become infinitesimally small (i.e., marginal utility grows infinitely large) when the income realization is low, initial debt is high and the borrowing constraint suddenly binds. Hence, they build up precautionary savings up to the point that at equilibrium the long-run level of bond holdings is above a minimum such that this is not possible under any triple $\psi$.

Precautionary savings does not imply that the economy jumps immediately out of initial high-debt regions in the short run. Figures 6 and 7 show the transitional dynamics of the conditional distribution of bond holdings starting from the largest debt position for $\sigma=2$ and $\sigma=$ 
5. With $\sigma=2$, the economy transitions out of the Sudden Stop range in about 6 quarters, but with $\sigma=5$ it takes about 50 quarters. The economy can take quite a while to build up the buffer stock of saving that allows it to part from the region of the state space in which it is exposed to Sudden Stops triggered by binding borrowing constraints resulting from productivity, interestrate and tax shocks. These transitional dynamics reflect the fact that, even though the model behaves in the long run as if it featured a maximum debt constraint, this constraint is not binding in the short run for optimal decision rules starting from initial conditions with high debt.

\subsection{Margin Requirements, Transactions Costs and Asset Prices}

The next application incorporates the use of a borrower's assets as collateral. As mentioned earlier, one type of collateral constraints is the one studied by Kiyotaki and Moore (1997), in which collateral is in the form of assets subject to a credible threat of confiscation by lenders in the event of default (with the credibility of the threat hinging on institutional arrangements that do allow lenders to confiscate assets). In this setting, lenders never lend more than the expected discounted liquidation value of the collateral. A second type of collateral constraints widely used in financial markets is in the form of margin requirements, which differ from K-M constraints in two key features. First, custody of the collateral is passed onto creditors when the debt is contracted, so there is no uncertainty regarding the lenders ability to confiscate the assets and the liquidation price. Second, the collateral constraint is set in terms of the current (or end-of-period) liquidation value of the collateral. Thus, a decline in asset prices triggers a "margin call" by which lenders require borrowers to fill in a gap between the contracted margin requirement and the market value of the collateral under the lenders' control. If borrowers fail to meet the call, lenders have the right to liquidate the assets. Some margin requirements exist as a regulatory practice by government agencies supervising financial intermediaries, others are set as 
clauses of credit contracts. Value-at-risk collateralization, in which lenders require collateral to cover worst-case-scenario losses are also a form of margin requirements.

Margin requirements on a subset of financial market participants in an environment of otherwise frictionless and efficient asset markets would be harmless from a macroeconomic standpoint. At least two additional asset-market frictions are needed to allow margin constraints to have non-trivial effects on intertemporal plans and asset prices. First, short positions must be constrained. If an agent faces a binding borrowing limit in the credit market, but borrowing by taking a sufficiently large short position on assets is feasible, any potentially binding credit constraint can be undone by setting debt to zero and going short on assets. Second, for asset prices to fall when margin constraints bind for some agents there must be frictions affecting asset trading. If a borrower's assets are sold to meet a margin call but aggregate asset demand is infinitely elastic at the fundamentals level, as it would be in a frictionless environment, the margin sale can be executed and the collateral restored without a drop in the asset price.

Consider an economy with similar preferences and technology as in the liquidityrequirements model but modified to introduce margin requirements and asset trading costs. This model economy is a variation of a heterogeneous-agents model with two agents: a small open economy and a representative foreign securities firm specialized in trading the equity of the small open economy. Since there is also a global credit market determining the world real interest rate on bonds, relative to which both the small open economy and the securities firm are very small, the large pool of lenders in world credit markets can be interpreted as representing a trivial third set of agents.

Firms producing inside the small open economy are the same as before, assuming now only a single tradable commodity for simplicity. Hence, the conditions that determine the 
demand for labor and dividends payments are standard marginal productivity conditions:

$$
\begin{aligned}
& w_{t}=\exp \left(\varepsilon_{t}\right) F_{n}\left(k, n_{t}\right) \\
& d_{t}=\exp \left(\varepsilon_{t}\right) F_{k}\left(k, n_{t}\right)
\end{aligned}
$$

for $t=0, \ldots, \infty$.

Preferences are the one-good version of those used in the liquidity-requirements model, so consumption in the argument of utility $\left(c-\frac{n^{\delta}}{\delta}\right)$ corresponds now to consumption of a single tradable good. Households maximize lifetime utility subject to this budget constraint:

$$
c_{t}=\alpha_{t} k d_{t}+w_{t} n_{t}+q_{t}\left(\alpha_{t}-\alpha_{t+1}\right) k-b_{t+1}+b_{t} R_{t}
$$

where $\alpha_{t}$ and $\alpha_{t+1}$ are beginning and end-of-period shares of the time-invariant domestic capital stock owned by domestic households and $q_{t}$ is the price of equity. For simplicity, the world's risk-free gross real interest rate is now assumed to be deterministic and tax shocks are ignored.

The margin requirement imposes the following borrowing constraint on households:

$$
b_{t+1} \geq-\kappa q_{t} \alpha_{t+1} k, \quad 0 \leq \kappa \leq 1
$$

This constraint limits the extent to which the small open economy can leverage its external debt position in the bond market using its equity holdings. The debt cannot exceed the fraction $\kappa$ of the value of end-of-period equity holdings. Note that, given the budget constraint (13), the margin constraint is equivalent to a flow constraint requiring that a fraction $1-\kappa$ of the economy's equity purchases be paid out of current saving (i.e., $\left.\alpha_{t} k\left(d_{t}+q_{t}\right)+w_{t} n_{t}+b_{t} R_{t}-c_{t} \geq(1-\kappa) q_{t} \alpha_{t+1} k\right)$.

In addition to the budget constraint and the margin requirement, the small open economy faces a constraint that imposes a lower bound on its equity position $\alpha_{t+1} \geq \chi$ for $-\infty<\chi<1$ for $t=1, \ldots, \infty$. As explained earlier, this lower-bound constraint is needed to ensure that the state 
space of the small open economy's optimization problem is compact and that the margin requirement is not irrelevant. A short-selling constraint is represented by $\chi \leq 0$ while $0<\chi<1$ can be interpreted as a portfolio requirement.

The optimality conditions of the maximization problem faced by households and firms in the small open economy imply that the equilibrium of the labor market, factor payments, and the level of output are determined by a set of static equilibrium conditions independent of the intertemporal elements of the model (particularly the dynamics of debt, equity and equity prices). This is because (a) the GHH specification of the argument of $u($.$) and v($.$) imply that the marginal$ rate of substitution between $c$ and $n$ depends on $n$ only, so labor supply is just a function of the real wage and does not shift with $c$, and (b) the demand for labor is given by the standard marginal productivity condition (11). These static labor demand and supply conditions determine the equilibrium sequences of $w_{t}, n_{t}$, and $\exp \left(\varepsilon_{t}\right) F\left(k, n_{t}\right)$ and given those condition (12) determines the equilibrium sequence of $d_{t}$. All of these sequences are stochastic because of the Markov process driving $\varepsilon$.

The representative foreign securities firm maximizes the present discounted value of the stream of dividends that it pays to its global shareholders. These firms are assumed to incur two types of costs in trading the small open economy's equity: recurrent and per-trade costs. These represent the costs that the firm incurs in gathering and processing information particular to the small open economy. Per-trade transactions costs are a common feature of the quantitative asset pricing literature (e.g, Heaton and Lucas (1996)). Recurrent costs are added to capture the notion that with regard to emerging markets, foreign traders face non-trivial recurrent costs to follow economic, political and social developments in the countries they invest in.

Calvo and Mendoza (2000b) argue that an arrangement where a pool of largely 
uninformed global investors invest in informed securities firms, that specialize in emerging markets and pay information costs, may be an endogenous feature of globalized financial markets. The reason is that in a world with short-selling constraints, a global investor's gain of acquiring country-specific information falls as the number of markets in which to invest grows.

The problem of the foreign traders is to choose $\alpha_{t+1}^{*}$ for $t=1, \ldots, \infty$ so as to maximize:

$$
D=E_{0}\left[\sum_{t=0}^{\infty} M_{t}^{*}\left(\alpha_{t}^{*} k\left(d_{t}+q_{t}\right)-q_{t} \alpha_{t+1}^{*} k-q_{t}\left(\frac{a}{2}\right)\left(\left(\alpha_{t+1}^{*}-\alpha_{t}^{*}+\theta\right) k\right)^{2}\right)\right]
$$

where $M_{0}^{*} \equiv 1$ and $M_{t}^{*}$ for $t=1, \ldots, \infty$ are the exogenous stochastic discount factors representing the trader's opportunity cost of funds or (at equilibrium) the marginal rates of substitution between $c_{t}$ and $c_{0}$ for the hypothetical world "representative client" of foreign securities firms. Since these firms are very small compared to the size of the global credit market, and since the model abstracts from collateral constraints on foreign traders, setting $M_{t}^{*}=R^{-t}$ is a reasonable assumption. Trading costs $q_{t}\left(\frac{a}{2}\right)\left(\left(\alpha_{t+1}^{*}-\alpha_{t}^{*}+\theta\right) k\right)^{2}$ are a function of the size of the trades $\left(\alpha_{t+1}^{*}-\alpha_{t}^{*}\right)$ and of a recurrent entry cost $\theta$. Even if the firm does not trade, it incurs each period a total recurrent cost equal to $q_{t}\left(\frac{a}{2}\right)(\theta k)^{2}$. The parameter $a$ is a "speed-of-adjustment" coefficient governing marginal transactions costs.

Define the fundamentals equity price $q_{t}^{f}$ as the conditional expected value of the stream of dividends discounted using the world's representative agent stochastic discount factors: $q_{t}^{f} \equiv E_{t}\left(\sum_{i=0}^{\infty} M_{t+1+i}^{*} d_{t+1+i}\right)$. It follows from the optimality conditions of the foreign trader's problem that: 


$$
\left(\alpha_{t+1}^{*}-\alpha_{t}^{*}\right) k=a^{-1}\left(\frac{q_{t}^{f}}{q_{t}}-1\right)-\theta
$$

Thus, foreign securities firms follow a partial-portfolio-adjustment rule by which their demand for equity is an increasing function of the percent deviation of the fundamentals equity price from the actual equity price. The price elasticity of this demand function is approximated by $1 / a$.

Given the probabilistic processes of the exogenous shocks and the initial conditions $\left(b_{0}, \alpha_{0}, \alpha_{0} *\right)$, a competitive equilibrium for this model is defined by sequences of state-contingent allocations $\left[c_{t}, n_{t}, b_{t+1}, \alpha_{t+1}, \alpha_{t+1}^{*}\right]$ and prices $\left[w_{t}, d_{t}, q_{t}\right]$ for $\mathrm{t}=0, \ldots, \infty$ such that: (a) domestic firms maximize dividends subject to the CRS production technology, taking factor and goods prices as given, (b) households maximize expected utility subject to the budget constraint, the margin constraint, and the short-selling constraint, taking as given factor prices, goods prices, the world interest rate and the price of equity, (c) foreign securities firms maximize the expected present value of dividends net of the trading costs, taking as given equity prices, and (d) the marketclearing conditions for equity, labor, and goods markets hold.

How do margin constraints and trading costs affect equilibrium asset prices and macroeconomics dynamics? While the lack of closed-form solutions imply that this question cannot be fully answered analytically, it is still possible to derive useful analytical results by examining the Euler equations for bonds and equity of the small open economy and the partialadjustment rule of foreign traders.

The Euler equations for $b_{t+1}$ and $\alpha_{t+1}$ in the small open economy can be manipulated to yield "partial-equilibrium" expressions for excess returns and equity prices as perceived by residents of this economy. These expressions are analogous to standard results from assetpricing models. The mean excess return on equity can be expressed as: 


$$
E_{t}\left[R_{t+1}^{q}\right]-R_{t+1}=\frac{\eta_{t}(1-\kappa)-\frac{v_{t}}{q_{t}}-\operatorname{COV}_{t}\left(\lambda_{t+1}, R_{t+1}^{q}\right)}{E_{t}\left[\lambda_{t+1}\right]}
$$

Here, $\lambda_{t}$ is the Lagrange multiplier on the small open economy's budget constraint (i.e., the lifetime marginal utility of $c_{t}$ ), $\eta_{t}$ is the multiplier on the margin requirement, $v_{t}$ is the multiplier on the short-selling constraint, and $R_{t+1}^{q} \equiv\left(d_{t+1}+q_{t+1}\right) / q_{t}$ is the return on equity.

Clearly, if the margin and short-selling constraints never bind, the expected excess return that households require to hold equity is determined by the negative of the covariance between $R^{q}{ }_{t+1}$ and $\lambda_{t+1}$ as in standard asset pricing models. If both constraints bind at date $t$ they affect expected excess returns via the direct and indirect effects identified by Heaton and Lucas (1996). The direct effects are given by $\eta_{t}(1-\kappa)$ and $-v_{t} / q_{t}$. A binding margin constraint increases the excess return by the amount $\eta_{t}(1-\kappa)$. A binding short-selling constraint reduces the excess return by $v_{t} / q_{t}$. The indirect effects depend on how the reduced ability to smooth consumption implied by these two frictions alters the covariance between the marginal utility of consumption and the return on equity. The covariance is negative for risky assets like equity, and it becomes more negative in the presence of frictions hampering consumption smoothing (although the resulting effect on unconditional excess returns has been found to be small in quantitative applications like that of Heaton and Lucas).

The small open economy's partial-equilibrium asset pricing equation reduces to:

$$
q_{t}=E_{t}\left(\sum_{i=0}^{\infty}\left[\prod_{j=0}^{i}\left(E_{t}\left[R_{t+1+j}^{q}\right]\right)^{-1}\right] d_{t+1+i}\right)
$$

where the sequence of $E_{t}\left[R_{t+1+j}^{q}\right]$ is given by (17). Thus, a binding margin requirement at any date $t+j$ for $\mathrm{j} \geq 0$ increases the expected return on equity that agents in the small open economy 
use to discount the future stream of dividends, and hence reduces their valuation of equity at $t$. Interestingly, date- $t$ equity prices fall whenever agents expect that there can be margin calls in the future, even if the margin constraint does not bind at $t$ (a result first noted in the closedeconomy model of margin requirements by Aiyagari and Gertler (1999)).

It follows from the above results that when a margin call takes place, agents in the small open economy rush to sell equity and adjust their debt position, and thus the equity premium they require increases. Since they meet in the equity market with foreign traders who are willing to buy the equity only if the price falls below the fundamentals level, the equilibrium equity price falls. However, this makes the margin constraint even more binding, triggering another round of margin calls in a downward spiral reminiscent of Irving Fisher's classic debt deflation mechanism.

By inverting the foreign traders demand function in (16), and imposing the marketclearing condition in the equity market, $\alpha_{t}+\alpha_{t}^{*}=1$ for all $t$, one finds that at equilibrium equity prices must satisfy $q_{t}=q_{t}^{f} /\left[1+a\left(\alpha_{t}-\alpha_{t+1}+\theta\right)\right]$. Thus, the magnitude of the equity price decline is larger the lower the elasticity of the foreign traders' demand curve (i.e., the higher is $a$ ). This is because the higher is $a$ the more the equity price needs to fall in order to entice foreign traders to buy the equity that the small open economy wishes to sell. As argued earlier, if their demand were infinitely elastic (i.e., $a=0$ ), the small open economy could reduce its equity holdings without lowering the price. Note also that, since the short-selling constraint imposes a lower bound on equity prices, the equity price collapse in response to a margin call is larger the larger the excess of initial equity holdings relative to the level of the short-selling constraint (i.e., the larger is $\alpha_{t}-\chi$ ). This is because a binding short-selling constraint limits the magnitude of the "fire sale" of equity that the small open economy can undertake. If the constraint binds, so 
$\alpha_{t+1}=\chi$, the fire sale of equity is larger the larger $\alpha_{t}$ is relative to $\chi$. If $\alpha_{t}=\chi$, no equity can be sold and the equilibrium market price must remain at $q_{t}^{f}$.

The recurrent trading costs also play an important role in the model's dynamics. If $M_{t}^{*}=R^{-t}$ and equity is a risky asset for the small open economy, a model with $\theta=0$ ends up in the long run with foreign traders owning the maximum equity that the short-selling constraint on domestic residents allows them to own $(1-\chi)$. This occurs because for any initial $\alpha_{t}$, the fact that equity is a risky asset for the small open economy implies that its valuation of equity is lower than that implied by discounting dividends at the risk free rate (i.e., lower than $q_{t}{ }^{f}$ ). However, at a price lower than $q_{t}^{f}$ the foreign trader is always buying equity. Hence, if an equilibrium exists, it will be at a price at which the small open economy sets $\alpha_{t+1}<\alpha_{t}$. Thus, in the long run domestic residents always hit the short selling constraint. On the other hand, if $\theta>0$ the equity price at which foreign traders chose a stationary equity position is lower than the fundamentals price, making it possible to obtain states of nature in which domestic agents may set $\alpha_{t+1} \geq \alpha_{t}$ at the equilibrium price.

The competitive equilibrium of this model is solved by reformulating it in recursive form and applying a recursive numerical solution method. To represent the equilibrium in recursive form, define $\alpha$ and $b$ as the endogenous state variables and $\varepsilon$ as the exogenous state. The state space of equity positions spans the discrete interval $\left[\chi, \alpha^{\text {max }}\right]$ with NA elements and the state space of debt position spans the discrete interval $\left[b^{\min }, b^{\max }\right]$ with NB elements. The endogenous state space is thus defined by the discrete set $Z=\left[\chi, \alpha^{\max }\right] \times\left[b^{\min }, b^{\max }\right]$ of NAxNB elements. Productivity shocks follow an asymptotically-stationary, two-point Markov chain with realizations $\varepsilon_{H}$ and $\varepsilon_{L}$, so the exogenous state space is defined by $E=\left\{\varepsilon_{H}, \varepsilon_{L}\right\}$. Since equilibrium 
wages, dividends and factor payments depend only on the realization of $\varepsilon$, these equilibrium outcomes can be expressed by the functions $w(\varepsilon), d(\varepsilon)$ and $n(\varepsilon)$.

Assume a continuous, nonnegative equity pricing function that is taken as given by foreign traders and the small open economy. This conjectured pricing function maps the state space into equity prices $q(\alpha, b, \varepsilon): E \times Z \rightarrow R^{+}$. For any initial state $(\alpha, b, \varepsilon)$, the conjecture must satisfy $q(\alpha, b, \varepsilon) \in\left[q^{\min }(\alpha, \varepsilon), q^{\max }(\alpha, \mathcal{E})\right]$, where $q^{\min }(\alpha, \varepsilon)=q^{f}(\varepsilon) /[1+a(\alpha-\chi+\theta)]$ and $q^{\max }(\alpha, \varepsilon)=q^{f}(\varepsilon) /\left[1+a\left(\alpha-\alpha^{\max }+\theta\right)\right]$ are the maximum and minimum equity prices along the foreign traders' demand curve for an initial state with equity holdings $\alpha$ and productivity shock $\varepsilon$. These bounds of the pricing function follow from the fact that when the small open economy hits either the short selling constraint or the upper bound $\alpha^{\max }$, the foreign traders are at the "short side" of the market (assuming the equity demand curves of both players are well-behaved with the one of the foreign traders always flatter than that of the small open economy).

Imposing market clearing in the equity market, the conjectured pricing function and the foreign trader's partial-adjustment decision rule can be combined to formulate the following conjectured transition equation for equity holdings:

$$
\hat{\alpha}^{\prime}(\alpha, b, \varepsilon)=\alpha-\frac{1}{a} *\left(\frac{q^{f}(\varepsilon)}{q(\alpha, b, \varepsilon)}-1\right)+\theta
$$

Taking as given the above conjectured transition equation and pricing function, and the equilibrium functions for factor payments and labor allocations, the dynamic programming problem for optimal consumption and bond holdings for the small open economy is: 


$$
V(\alpha, b, \varepsilon)=\max _{b^{\prime}}\left\{\frac{\left[c-\frac{n(\varepsilon)^{\delta}}{\delta}\right]^{1-\sigma}-1}{1-\sigma}+\exp \left(-\beta\left[\operatorname{Ln}\left(1+c-\frac{n(\varepsilon)^{\delta}}{\delta}\right)\right]\right) E\left[V\left(\hat{\alpha}^{\prime}(\alpha, b, \varepsilon), b^{\prime}, \varepsilon^{\prime}\right)\right]\right\}
$$

subject to:

$$
\begin{gathered}
c=\alpha k d(\varepsilon)+w(\varepsilon) n(\varepsilon)+q(\alpha, b, \varepsilon) k\left[\alpha-\hat{\alpha}^{\prime}(\alpha, b, \varepsilon)\right]-b^{\prime}+b R \\
b^{\prime} \geq-\kappa q(\alpha, b, \varepsilon) \hat{\alpha}^{\prime}(\alpha, b, \varepsilon) k
\end{gathered}
$$

The solutions to this problem represent optimal consumption and bond accumulation choices by the small open economy for any given conjectured pricing function and corresponding equity transition equation. These optimal plans can then be used together with the asset pricing formulas in (17) and (18) to compute the actual equity pricing function, $\tilde{q}(\alpha, b, \varepsilon)$, at which the small open economy would agree to the trades implicit in the conjectured pricing and equity transition equations in a competitive equity market. In general, for an arbitrary initial conjectured pricing function, the conjectured and the actual equity pricing functions will differ. An updated conjectured pricing function can then be created using a Gauss-Seidel algorithm until the distance between the two functions satisfies a reasonable convergence criterion. ${ }^{6}$

The optimal decision rules obtained after the conjectured and actual pricing functions converge constitute a recursive competitive equilibrium for the model. In a recursive equilibrium, the optimal rules determining equity holdings, bond holdings, consumption, labor, wages, dividends, foreign equity holdings and the equity pricing function are such that: (a) given equity prices, wages and dividends, the policy functions for $c, b^{\prime}, \alpha^{\prime}$ and $n$ solve the maximization problems of households and firms in the small open economy, (b) given equity

\footnotetext{
${ }^{6}$ Since this "hog cycle" algorithm is not a contraction mapping, the Gauss-Siedel algorithm uses dampening and extrapolation corrections to improve accuracy and avoid exploding cycles.
} 
prices and dividends, the policy function for $\alpha^{\prime}$ solves the maximization problem of foreign traders, and (c) the market-clearing conditions for equity, goods and labor markets hold. ${ }^{7}$

This model is calibrated and solved in Mendoza and Smith (2001) using similar parameters as in Mendoza (2002). The experiments conducted here use the same calibration and discretized state space. Mendoza and Smith constructed a benchmark calibration in which an RBC-like calibration exercise determines the values of the parameter set $(\gamma, \sigma, \beta, \delta, R)$ and the properties of the Markov process of productivity shocks. The parameters values are $\gamma=0.341$, $\sigma=1.1, \beta=0.04518, \delta=2$ and $R=1.065^{1 / 4}$. The values of $\gamma, \beta$ and $R$ are derived from Mexican data (see Mendoza and Smith for details). The value of $\sigma$ is in line with values used in the RBC literature, although it is lower than available estimates for Mexico. The value of $\delta$ is set to yield unitary wage elasticity in labor supply. The standard deviation of productivity shocks is set to match that of Mexico's GDP of tradable goods in quarterly data (3.36\%), and the transition probability matrix is assumed to be symmetric with a conditional probability of switching states set to match the first-order-autocorrelation of Mexico's tradables output (0.553). The values of the financial frictions parameters $(\kappa, \chi, a, \theta)$ are set first to baseline values such that the margin constraint is not binding in all of $E x Z$, and then $\kappa$ is increased to obtain a binding margin constraint. The baseline values are $\theta=0, a=0.001$ and $\chi=0.8742$, which support unconstrained equilibrium allocations with any $\kappa \geq 0.011$ for grids with 130 evenly-spaced bond positions in the

${ }^{7}$ This is easy to prove noting that: (i) the Benveniste-Sheinkman equation applied to problem (20) yields the same Euler equation for bond holdings as the households maximization problem, (ii) by construction, the implied equity prices ensure that at equilibrium the households' Euler equation for equity holdings also holds (up to the error allowed by the convergence criterion), (iii) the wage, dividend and labor functions reflect optimal decisions by households and domestic firms, (iv) the conjectured transition equation for equity holdings ensures that the trades undertaken at the equilibrium equity prices solve the maximization problem of foreign traders, and (v) the constraints (21) and (22) combined with results (i)-(iv) ensure that the market 
interval [-0.634, 5.691] and 76 evenly-spaced equity positions in the interval [0.874,0.969]. The simulation with binding margin requirements uses $\kappa=0.009$.

The simulations reviewed below differ from those in Mendoza and Smith (2001) in two respects. First, Mendoza and Smith implemented a different solution method that does not use a conjectured transition equation for asset holdings in the small open economy, but instead solves separately for equity and bond decisions rules for the small open economy and foreign traders, and iterates to convergence on a conjectured pricing function that clears the equity market. Second, Mendoza and Smith focused on solutions for the case in which $M_{t}{ }^{*}$ is set so that in the absence of financial frictions no equity trading takes place at equilibrium, instead of setting the traders' stochastic discount factors to match the world interest rate. The no-trading equilibrium is computed by solving the dynamic programming problem of the small open economy imposing stationary equity holdings, calculating the corresponding stochastic discount factors $M_{t}$ for the households of that economy, and then setting $M_{t}^{*}=M_{t}$.

The manifolds of the optimal decision rule for bond holdings in economies with and without margin constraints (for the low realization of the shock) are plotted in Figure 8. Manifolds of the corresponding equity prices are plotted in Figure 9. Note that in the manifolds for the margin-constrained economy there is a "low-wealth" triangular valley that should be ignored because $\alpha$ and $b$ are too low for the non-negativity constraint on the argument of utility to be satisfied together with the margin constraint. In each plot, this area is set to show values of the variable being plotted equal to the value that corresponds to the lowest $(\alpha, b)$ pair for which a solution satisfying the non-negativity constraint exists.

Figure 8 shows that, even in this experiment with a very high elasticity in the equity

clearing conditions, the households' budget constraint, and the margin constraint are satisfied. 
demand of foreign traders (at $a=0.001$ the elasticity is 1000) and no recurrent trading costs, the suddenly-binding margin constraint alters significantly foreign asset holdings. The difference in bond positions is striking, as the decision rule changes from a smooth, increasing function of $\alpha$ and $b$ to a non-linear function with a sharp jump at the point in which debt is sufficiently high for the margin constraint to bind. The jump is larger the higher is $\alpha$ because these are also the states in which the equity price falls by more (see Figure 9), and hence the Fisherian effect inducing tighter margin constraints in response to falling asset prices is stronger. However, the equity price collapses were bound to be quantitatively small given that the very high elasticity of the foreign traders' demand for equity implies that their demand curve is almost horizontal at the level of the fundamentals price.

The impact effects on consumption and the current account-output ratio in response to a switch from the high productivity state to the low productivity state are plotted in Figures 10 and 11 respectively. Figure 10, in combination with Figures 8 and 9, shows a key difference between this application and the liquidity requirements model: with two assets to allocate savings into, agents have an extra degree of freedom in their efforts to mitigate the consumption effect of a binding borrowing constraint. As Figure 10 shows, in states in which debt is high enough for the constraint to bind but initial equity holdings are large, agents manage to keep a relatively smooth consumption path (despite the large adjustments in both equity prices and bond holdings shown in Figures 8 and 9). In states in which agents have a low equity position, consumption falls sharply. The largest consumption declines are observed when the margin constraint switches from nonbonding to binding when the productivity shock hits, they can reach up to 11.5 percent. Figure 11 shows a similar pattern for the response of the current accountoutput ratio. Small reversals of current account deficits occur in response to the productivity 
shock in the area of the state space in which the consumption impact effect is modest, but reversals of up to 2.5 percentage points of GDP are possible when the consumption decline is at its maximum. Mendoza (2002) is taking this analysis further to examine the implications of varying the elasticity of the trader's demand curve, the size of recurrent costs, and the coefficient of the margin requirement, as well as introducing interest-rate and tax shocks similar to those used in the model with liquidity requirements.

\subsection{Borrowing Constraints Enforcing Participation Constraints}

Liquidity requirements and collateral constraints are features of a variety of private credit contracts but when it comes to instruments like sovereign debt there is very limited scope for enforcing contracts featuring those constraints. In this context, a modeling approach based on willingness-to-pay considerations seems an appealing alternative. Hence, in this application we study a small open economy that faces a standard credit-market participation constraint. In case of default, the country is punished by permanent exclusion of world financial markets, so default is optimal whenever the expected lifetime utility of staying in a credit relationship exceeds that of living permanently under financial autarky.

The analysis conducted here differs from those in Kehoe and Levine (1993), Kocherlakota (1996), Kehoe and Perri (2002) and Alvarez and Jermann (2000) in that the model retains the asset-market incompleteness of the small-open-economy RBC setting, in contrast with the complete-contingent-claims markets assumed in those studies (which were not aimed at explaining Sudden Stops but at studying equilibria in which there can be as much risk sharing as possible given that participation constraints are satisfied). As Alvarez and Jermann (2000) showed, the equilibrium with participation constraints and complete markets can be decentralized with financial markets that feature endogenous, state-contingent limits on short 
positions for state-contingent assets. Interestingly, the incomplete-markets, small open economy RBC model with a participation constraint can also be represented as an economy that faces an endogenous borrowing constraint, but with the caveat that the constraint is not state contingent. This brings the model closer to the analysis of participation constraints under incomplete markets by Zhang (1997) than to the models in the Kehoe-Levine-Kocherlakota line.

In the model we review below, precautionary savings interact with default incentives to give rise to the endogenous non-state-contingent borrowing constraint, which ensures that agents have incentives to repay their debts, and thus enforces the participation constraint. The borrowing constraint is determined by the highest level of foreign asset holdings for which the expected lifetime utility of staying in a credit relationship is equal to the expected lifetime utility of autarky across all productivity states of nature. This is the case because the model's only financial asset is the non-contingent bond and the decision to default is made one period in the future. In this environment, lenders seeking to enforce participation constraints in all states of nature need to set a borrowing limit equal to the maximum $b_{t+1}$ among those for which repayment and autarky values are equalized across all realizations of the productivity shock tomorrow. As a consequence, the borrowing constraint cannot vary with the state of nature. Consider a one-sector small open economy model similar in structure to the one examined in the previous application. The small open economy can be viewed as a representative-agent economy facing a labor/leisure choice and non-diversifiable, idiosyncratic income risk. Labor allocations, dividends and wages are still governed by the same equilibrium functions of the productivity state $w(\varepsilon), d(\varepsilon)$ and $n(\varepsilon)$. The utility function changes only in that it features now a constant discount factor. Thus, this application obtains a well-defined limiting distribution of foreign assets for the small open economy, even in the absence of the participation 
constraint, via precautionary savings, as in the canonical model of Aiyagari (1994) with an exogenous borrowing constraint. This requires the condition $\beta(1+r)<1$.

The households' budget constraint is:

$$
c_{t}=d_{t}+w_{t} n_{t}-b_{t+1}+b_{t} R_{t}
$$

This constraint differs from the one in (13) only in that domestic agents are owners of the entire domestic capital stock (with $k=1$ without loss of generality).

The small open economy also faces a standard participation constraint that ensures that it always has the incentive to repay its external debt:

$$
V\left(b_{t+1}, \varepsilon_{t+1}\right) \geq V^{A U T}\left(\varepsilon_{t+1}\right) \text { for all } b_{t+1}, \varepsilon_{t+1}
$$

The value of autarky in the right-hand-side of (24) is state-dependent since it measures the expected utility of the optimal consumption-labor path obtained when consumption is set equal to domestic output at all times, and both labor and output vary with the productivity shock. Under autarky, the small open economy cannot smooth period utility because there are no international financial assets available to facilitate consumption smoothing after it goes in default. The value of autarky solves the following straightforward functional equation:

$$
V(\varepsilon)=\frac{\left(d(\varepsilon)+w(\varepsilon) n(\varepsilon)-\frac{n(\varepsilon)^{\delta}}{\delta}\right)^{1-\sigma}-1}{1-\sigma}+\beta E\left[V\left(\varepsilon^{\prime}\right)\right]
$$

The competitive equilibrium for this economy is defined by sequences of state contingent allocations and prices $\left[c_{t}, n_{t}, b_{t+1}, w_{t}\right]$ for $t=1, \ldots, \infty$ such that: (a) domestic firms maximize profits given their production technology, taking factor prices as given, (b) households maximize expected lifetime utility subject to their budget constraint and participation constraint, taking as 
given factor prices and the world interest rate, (c) international lenders agree to loan contracts that enforce participation constraints, and (d) the goods and labor markets clear.

Given that the value function in the left-hand-side of (24) is increasing and concave in foreign bond holdings, one can translate the participation constraint into an endogenous constraint setting a maximum amount of debt (or minimum level of bond holdings), $\underline{B}$, that guarantees that condition (24) holds regardless of the realization of the productivity shock:

$$
b^{\prime} \geq \underline{B}=\max _{\varepsilon}\left\{\underline{b}(\varepsilon): V(b, \varepsilon)=V^{A U T}(\varepsilon)\right\}
$$

This borrowing constraint ensures that the only permissible values of $b^{\prime}$ at equilibrium are those greater or equal to the largest one, across all productivity states of nature, for which the value of debt repayment equals the value of living in financial autarky.

Clearly, the level of the borrowing constraint is determined by the default incentives of the small open economy (i.e., by the autarky and continuation values). However, it is not straightforward to know how the gap between these two values depends on preferences, technology, initial debt, and the stochastic structure of productivity shocks. However, it is important to separate this question (i.e., how is $\underline{B}$ determined) from the question of whether this model can reproduce Sudden Stops (i.e., situations in which the borrowing constraint switches from nonbonding to binding as the productivity shock switches from high to low). Once $\underline{B}$ is set, the model's solution is identical to that of a small open economy model with an exogenous, state- and time-invariant lower bound on foreign assets that just happens to have been set at $\underline{B}$. This yields similar incentives for precautionary savings and long-run distributions of assets as the Aiyagari (1994) incomplete-markets model with exogenous borrowing constraints. In particular, the decision rule $b^{\prime}(b, \varepsilon)$ first equals $\underline{B}$ for low values of $b$ and all values of $\varepsilon$, then at some level of $b$ (which is lower for lower values of $\varepsilon$ ) it hits a kink and slopes upward for higher 
values of $b$. This allows for the possibility that there can be a range of values of $b$ for which the borrowing constraint does not bind if productivity is high but it becomes binding if productivity is low, and in this range the model will display Sudden Stop effects.

The non-state-contingent nature of $\underline{B}$ does limit this model 's ability to yield short-term dynamics in which the real effects of Sudden Stops can be very large and prevents it from producing outcomes in which the likelihood of Sudden Stops may persist several quarters. The reason is that, in contrast with the previous two applications in which the borrowing constraint varies with the state (either with GDP in units of tradables or with the end-of-period liquidation value of equity), here the constraint is always $\underline{B}$. The economy cannot be assumed to start from higher debt positions because, by backward induction, this would imply that at some point in the past lenders agreed to debt contracts that did not support the participation constraint. Even if they did, the reversal to $\underline{B}$ would take place in one shot.

The manner in which default incentives are influenced by preferences, existing debt and the Markov structure of shocks is also worth further discussion. The effect of initial debt is obvious: since the value of repayment is increasing in $b$, the incentive for default is always higher the higher the level of debt the country has acquired. The effects of the productivity shocks are easiest to study in the case of a two-point, symmetric Markov chain, with high and low shocks denoted $\varepsilon^{l}$ and $\varepsilon^{h}$ respectively, such that $\varepsilon^{h}=-\varepsilon^{l}=\varepsilon$ and the variance of the shocks is $\varepsilon^{2}$. In this case, the value of repayment is low, the lower the realization of the productivity shock and the higher the conditional probability of continuing in the low state of the shock. The value of autarky is high, the higher the productivity shock and the higher the conditional probability of continuing in the high state of the shock. For given conditional probabilities (i.e., given the persistence of the productivity disturbances), higher variance increases debt repayment 
incentives, since higher variance increases the benefit of using international debt as a means to smooth consumption.

The households' coefficient of relative risk aversion matters for default incentives because it influences the curvature of the utility and value functions. For low values of this curvature parameter, the borrowing constraint that supports the participation constraint tends to correspond to the level of debt at which repayment and autarky values are equal when the productivity shock is high. In this case, incentives to default are higher in good productivity states. However, for sufficiently-high relative risk aversion, everything else the same, the borrowing constraint that supports the participation constraint is the level of debt at which repayment and autarky values are equal when the productivity shock is low. The intuition is that with greater curvature in utility, an agent hit by a negative productivity shock has a higher marginal utility of lower consumption and is thus more willing to default to get a higher consumption level under autarky, than an agent with less curvature in utility.

The controversial implication derived from these arguments is that the model can easily predict that, looking at a cross section of small open economies all assumed to be identical in preferences and technology, those with more macroeconomic volatility (i.e., higher income variability) should be observed to be the ones with a higher capacity to borrow (or with lower values of $\underline{B}$ ). This is because the high-volatility economies enjoy more benefits from being able to smooth consumption using the global credit market and thus have less incentives to default. Note, however, that higher volatility by itself is not sufficient to ensure that the borrowing constraint of a high-volatility country will be set at a higher level than for a low-volatility country because this depends on the combination of the preference, technology and stochastic factors mentioned above. 
The solution method used to solve this model is a policy function iteration algorithm that solves recursively for the endogenous borrowing constraint defined in (26). We start with a guess of $\underline{B}$ and solve the model via policy function iteration on the bond holding decision rules in the corresponding Euler equation. We then calculate the value of expected lifetime utility given the optimal decision rules for the given guessed value of $\underline{B}$ and the utility of autarky, and evaluate whether the preset borrowing constraint is the least tight that enforces the participation constraint in all productivity states. If it is not, we find the levels of bond holdings that support the participation constraints with equality for all states, and choose the maximum among these as the new guess of $\underline{B}$. The iterations continue until the guess value of $\underline{B}$ set in the first step equals the endogenous constraint computed in the last step. This method is very similar to the one employed by Zhang (1997).

The numerical results reported below illustrate some of the properties of the model explained in the previous paragraphs. Results are reported for two experiments that compare repayment incentives and borrowing constraints for economies with risk aversion coefficients set at 2 and 5 respectively. Table 3 presents the parameter values used in the two experiments. Figure 12 plots the values of repayment and autarky under high and low productivity states as a function of the foreign bond position. These plots show how in the $\sigma=2$ case the borrowing constraint is set at the level in which repayment and autarky values cross under the high productivity state, while for $\sigma=5$ this happens at the debt position the equates the repayment and autarky values under the low productivity state.

Figure 13 shows the limiting distribution for bond holdings for the economy with $\sigma=5$, which is similar to the ergodic distribution of foreign assets in the liquidity requirements economy. Recall, however, that while there are transitional dynamics in the conditional 
distributions of foreign assets in the liquidity requirements economy when the simulations start from high levels of debt relative to those supported by the ergodic distribution, the model with the participation constraint can never start from debt levels higher than $-\underline{B}$ because that would imply that at the time such high debt was acquired the participation constraint did not hold. Even if one assumed that such an initial high-debt state could be observed, the economy would have to jump to $\underline{B}$ in one shot.

Figure 14 shows impact effects on consumption and foreign asset holdings when the economy switches from a high productivity shock to a low productivity shock for the $\sigma=5$ experiment. As in the previous applications, a switch from a state where the constraint is not binding to a state where it binds has large effects on consumption and foreign asset holdings. However, the effects are quantitatively smaller in part because the parameterizations and the models themselves are not entirely comparable, but also because the model with the participation constraint can only accommodate initial debt positions that satisfy the borrowing constraint $\underline{B}$.

Summing up, the willingness-to-pay model based on a participation constraint under incomplete markets can reproduce some features of the crises of emerging markets, but in some dimensions it seems to fall behind the ability-to-pay alternatives. In particular, it can yield a counterfactual prediction regarding macroeconomic volatility and the ability to acquire debt in global credit markets, and it limits the magnitude and persistence of the Sudden Stops it can produce because of its non-state-contingent endogenous borrowing constraint. At the same time, however, this model has the advantage that it endogenously enforces full consistency in the incentives of borrowers and lenders, while the previous applications rely on the implicit assumption that the frictions they assumed are enough to commit debtors to repay even if debtors are in states in which they could be better off living under autarky. 


\subsection{Capital Accumulation, Collateral Constraints and Tobin's q}

From the perspective of a business cycle analysis, an important element missing from the previous three applications is capital accumulation. The interaction of credit frictions, the price of capital, and the investment process is an important subject to explore as part of the businesscycle implications of financial-market imperfections. Thus, in this last application we consider a full-blown RBC small open economy model with capital accumulation in which foreign debt must satisfy a collateral constraint. The collateral constraint is again in the form of a margin requirement set to a fraction of the end-of-period liquidation value of the capital stock. In this environment, the equilibrium price of equity must satisfy the households' forward-looking asset pricing condition as well as the firms' optimality condition for investment decisions.

The model shares with the asset-pricing model reviewed earlier, the assumption that a margin requirement forces households to keep their debt equal or smaller than a fraction $\kappa$ of the value of the capital stock. This model differs in that all equity is held by the domestic representative agent and capital accumulation is endogenous.

Firms in this economy have a more dynamic role than in the previous models. They choose labor and investment to maximize the present value of their profits taking as given wages and the cost of funds. Firms operate a constant-returns-to- scale technology and face convex adjustment costs of investment. Firms choose $n_{t}, i_{t}$, and $k_{t+1}$ to maximize the expected present discounted value of profits:

$$
E_{0}\left[\sum_{t=0}^{\infty}\left(\prod_{j=0}^{t}\left(\tilde{R}_{j}\right)^{-1}\right)\left(\exp \left(\varepsilon_{t}\right) F\left(k_{t}, n_{t}\right)-w_{t} n_{t}-i_{t}\left[1+\varphi\left(\frac{i_{t}}{k_{t}}\right)\right]\right)\right]
$$

where $\tilde{R}_{0}=1$ and $\tilde{R}_{j}$ for $j=1, \ldots, \infty$ are the stochastic discount factors (or, at equilibrium, the marginal rates of substitution in consumption between date $j-1$ and date $j$ ) that represent the cost 
of funds to firms. This maximization problem is subject to the standard capital accumulation equation:

$$
i_{t}=k_{t+1}-k_{t}(1-\delta)
$$

Note that equation (27) implicitly assumes that firms cannot borrow directly form abroad because profits are not discounted at the world interest rate. However, the result that at equilibrium firms discount profits with the households' stochastic discount factors implies that the model allows for households, who can borrow from abroad and are the owners of the firms, to provide financing to firms at the interest rate that they find optimal to do so.

The first-order conditions of the firm's problem are:

$$
\begin{gathered}
\exp \left(\varepsilon_{t}\right) F\left(k_{t}, n_{t}\right)=w_{t} \\
\left(1+\varphi\left(\frac{i_{t}}{k_{t}}\right)+\left[\frac{i_{t}}{k_{t}}\right] \varphi,\left(\frac{i_{t}}{k_{t}}\right)\right)=q_{t} \\
E_{t}\left[\left(\tilde{R}_{t+1}\right)^{-1}\left(\exp \left(\varepsilon_{t+1}\right) F_{K}\left(k_{t+1}, n_{t+1}\right)+\left[\frac{i_{t+1}}{k_{t+1}}\right]^{2} \varphi^{\prime}\left(\frac{i_{t+1}}{k_{t+1}}\right)+(1-\delta) q_{t+1}\right)\right]=q_{t}
\end{gathered}
$$

where $q_{t}$ is the Lagrange multiplier corresponding to the capital accumulation equation at time $t$, or the firms' shadow value of investing in one additional unit of capital. These optimality conditions are standard from investment theory. Equation (29) is the standard labor demand condition. Equation (30) equates the marginal cost of investment with its shadow value, and it implies that investment is an increasing function of $q_{t}$ because the marginal cost is increasing in the investment-capital ratio and capital is predetermined one period in advance. Equation (31) equates the expected discounted marginal return of investment to its shadow value.

The Euler equation also represents an arbitrage condition in implicit form that equates (at equilibrium) the expected marginal gain of adding an extra unit to the capital stock weighed by 
the households' stochastic intertemporal marginal rate of substitution in consumption with the marginal cost. The expected marginal gain includes dividend payments $d_{t+1}$, defined as $d_{t+1} \equiv \exp \left(\varepsilon_{t+1}\right) F_{K}\left(k_{t+1}, n_{t+1}\right)+\left[\frac{i_{t+1}}{k_{t+1}}\right]^{2} \varphi^{\prime}\left(\frac{i_{t+1}}{k_{t+1}}\right)$, plus capital gains net of depreciation. The forward solution of equation (31) yields an asset-pricing expression for the firm's valuation of capital as a function of the expected present discounted value of dividends.

$$
(1-\delta) q_{t}=E_{t}\left[\sum_{j=0}^{\infty}\left(\prod_{i=0}^{j}\left(\frac{\tilde{R}_{t+1+i}}{(1-\delta)}\right)^{-1}\right) d_{t+1+j}\right]
$$

The households' optimization problem is to maximize expected lifetime utility (returning now to the SCU utility function in equation (1)) subject to the following budget constraint:

$$
c_{t}=\left(d_{t}+q_{t}(1-\delta)\right) k_{t}-q_{t} k_{t+1}+w_{t} n_{t}-b_{t+1}+b_{t} R_{t}
$$

The collateral constraint implies that households are allowed to borrow up to a fraction $\kappa$ of the end-of-period value of the capital stock:

$$
b_{t+1} \geq-\kappa q_{t} k_{t+1}
$$

The household's problem yields an asset-pricing condition similar to the one derived in application 4.2 (eq. (17)) with an additional depreciation component. In a decentralized competitive equilibrium, households solve their optimization problem taking equity prices, dividends and wage rates as given. Their valuation of equity reflects the expected present discounted value of the stream of state-contingent dividends, discounted using the sequence of their stochastic discount factors (i.e., the marginal rates of substitution in consumption between date $t+1+j$ consumption and date $t$ consumption, for $j=0, \ldots, \infty$, adjusted to take into account the states in which the collateral constraint binds).

In a rational expectations equilibrium, the equity prices resulting from the households' 
asset-pricing equation must match those obtained from the firm's investment-demand decision in equation (32). In other words, at equilibrium the sequence of stochastic discount factors of households, taken as given by firms in solving their optimization problem, must yield equity prices from the firms' side such that, taken as given those prices, the households' optimization problem yields the same sequence of stochastic discount factors.

It is possible to use the above characterization of the equilibrium, combined with the representative-agent nature of the model, to write down a recursive formulation of the competitive equilibrium in the form of a planner's problem for the small open economy that takes as given a conjectured equity price function. The planner's problem can be solved repeatedly until convergence is attained between the conjectured pricing function and the actual prices calculated using the values of the households' stochastic discount factors obtained each time the planner's problem is solved. The conjectured pricing function can be updated at each stage using a Gauss-Siedel algorithm like the one proposed for application 4.2. Moreover, the investment schedule implied by equation (30) can play the same role played by the trader's partial-portfolio adjustment rule in that other application (i.e., it can be used to build a conjectured transition equation for aggregate capital given the conjectured pricing function and the initial capital stock).

Since this model's collateral constraint is a function of the capital accumulation decision, it introduces feedback effects between the constraint (or the incentives to relax it) and the production and investment decisions, wage and dividend rates, and the price of capital. Suppose a realization of the exogenous shocks makes the collateral constraint bind. If equilibrium investment declines as households try to reduce their equity stake to lessen the effect of the suddenly-binding constraint on consumption, the price of capital falls by equation (30). This 
tightens further the constraint producing a Fisherian deflationary effect as in the equity-trading model. In contrast with that model, however, the change in capital accumulation introduces effects that persist over time on the ability of the economy to generate income, as the independence of the equilibrium paths of labor allocations and wage and dividend rates with respect to the credit friction does no longer hold. We are examining the quantitative implications of this model and its ability to explain Sudden Stops in work in progress.

\section{Conclusions}

The seven years separating the Mexican financial crisis of December 1994 and the recent Argentine crisis witnessed more than a dozen similar financial debacles across the majority of the so-called emerging-markets economies. The novel feature of these crises was that they featured four empirical regularities that are now collectively referred to as the Sudden Stop phenomenon: a sudden loss of access to international capital markets, a marked reversal of the current account deficit, a severe contraction of domestic production and aggregate demand, and a collapse in asset prices and in domestic relative prices. Emerging markets crises also displayed a high potential for contagion, as a crisis in one country infected other emerging economies with little or no direct economic linkages with the first one.

Explaining Sudden Stops poses a serious challenge to international macroeconomic theory because their features are seriously at odds with the predictions of the mainstream approaches to analyze balance-of-payments crises and economic fluctuations in open economies. As a result, a growing literature has produced several alternative theoretical models in which financial-market imperfections are put forward as a central element of the transmission mechanism that triggers Sudden Stops and contagion of crises across emerging markets. Quantitative applications of this financial-frictions approach have lagged behind, however, and 
hence the potential for this approach to offer a plausible explanation for the Sudden Stops phenomenon and a solid basis for policy-evaluation models remains undetermined.

This paper surveyed recent developments in an area of quantitative applications of openeconomy equilibrium business-cycle models with financial frictions that aim to fill some of the gaps in the literature on emerging markets crises. The applications featured explicit constraints on a small open economy's ability to borrow from international capital markets linked to abilityto-pay and willingness-to-pay criteria like those at the core of several theoretical and policy studies on Sudden Stops. These borrowing constraints were attached to the optimization problems of economic agents acting independently in a decentralized competitive environment, and the resulting equilibria were then represented as solutions to recursive planning problems. The planning problems were solved with recursive, nonlinear numerical methods that are accurate for picking up the kinks in foreign asset decision rules and the implied nonlinearities in the adjustment of macroeconomic aggregates caused by suddenly binding borrowing constraints.

The first application considers a two-sector variant of the standard RBC model for small open economies without capital accumulation in which lenders impose a liquidity requirement condition on borrowers, by which they must pay a fraction of their current obligations out of current income. Given the households' budget constraint, the liquidity requirement is equivalent to a borrowing constraint limiting the stock of foreign debt not to exceed a fraction of income. The liquidity requirement can thus be interpreted as a tool for reducing the risk of borrowers becoming unable to service their debt, and is in line with lending criteria widely applied in credit markets (particularly mortgage and consumer credit markets). The two-sector nature of the model plays a key role because foreign debt is denominated in units of tradable goods but part of the income on which it is leveraged is generated in the nontradables sector. This allows the 
model to capture the "liability-dollarization" problem faced in many emerging markets crises: sudden changes in the relative price of nontradables in terms of tradables, or in the income generated by the nontradables sector, compromise the ability of borrowers to service debt and contribute to magnify the effects of the loss of access to world credit markets.

The second application explores equity trading and its connection with access to international credit markets in a two-agent stochastic general equilibrium asset-pricing model with financial frictions. The model features a one-good version of the same small open economy setup as the first application but modified to allow domestic agents to trade domestic equity abroad and to require them to offer their equity holdings as collateral for foreign debt. Collateral is modeled in the form of a margin requirement according to which debt is limited not to exceed a fraction of the end-of-period liquidation value of the domestic agents' equity position. This form of collateral is widely used in international capital markets through value-at-risk collateralization or explicit margin call clauses (such as those that featured prominently in the contagion of the Russian crisis to financial markets worldwide), and it is also often imposed on financial intermediaries by regulatory agencies. Domestic agents trade equity with specialized, value-maximizing foreign securities firms that incur per-trade and recurrent trading costs in trading the small open economy's equity.

A margin call in this setup leads domestic agents to engage in a "fire sale" of equity in their effort to meet the call and minimize the adverse welfare implications of the suddenly binding credit constraint. However, the trading costs incurred by foreign traders imply that their equity demand function is less than infinitely-elastic. Hence, the fire sale of equity lowers equity prices below the fundamentals level and tightens further the borrowing constraint, thereby inducing a new round of margin calls in a deflationary spiral reminiscent of the Fisherian debt 
deflation mechanism.

The third application switches from the ability-to-pay frictions examined in the first two applications to examine a model with a willingness-to-pay constraint. In particular, this application revisits the one-good RBC small open economy model without capital accumulation in an environment in which the economy is required to satisfy a credit market participation constraint. This constraint requires the expected lifetime utility of repaying debts not to fall below the expected lifetime utility of moving to financial autarky, under the assumption that the latter means permanent exclusion of the global credit market. A recursive representation of the equilibrium of this economy features an endogenous borrowing constraint that does not vary over time and across states of nature. This constraint is set at the highest level of debt at which the values of participation and autarky are equalized across all possible realizations of an exogenous productivity disturbance.

The last application reconsiders collateral constraints in a full-blown RBC small open economy with endogenous investment decisions and capital-adjustment costs. In this case, households cannot borrow more than a fraction of the end-of-period liquidation value of the capital stock, which is entirely held by domestic agents. In the recursive competitive equilibrium, the optimality conditions of the firms' investment plans in this Tobin's q-type model can be used to build conjectured functions for the price of capital and the transition equation of the aggregate capital stock. The economy's optimal consumption and foreign debt accumulation plans, given these conjectures, can be solved for repeatedly until convergence is achieved between the conjectured capital pricing function and the forward solution for the price of capital consistent with the optimal consumption plans.

Endogenous capital accumulation adds a vehicle for increasing the persistence of the 
macroeconomic effects induced by a suddenly binding collateral constraint. The reason is that this model features the standard inverse relationship between the price of capital and the investment decision. Hence, the decline in the price of capital caused by the agents' rush to liquidate capital to relax the collateral constraint leads not only to a Fisherian effect like the one in the equity trading application but it also lowers the future capital stock and impairs the economy's ability to generate future wage and dividend income. The decline in expected earnings feeds back into the price equity and thus interacts with the Fisherian effect.

Much remains to be done in the task of developing quantitative applications of equilibrium business cycle models that can explain the Sudden Stops phenomenon, yet the results summarized in this paper suggest that models based on credit frictions can produce large current account reversals and collapses in economic activity and prices. Moreover, the precautionary savings channel inherent to all four applications enables the models to be consistent with the observation that while Sudden Stops are large and dramatic, and can entail large welfare costs (see Mendoza (2001)), they tend to be relatively rare compared with the regular business cycle of the economies in question. In addition, the four applications break away from the common assumption in the emerging-markets-crises literature of treating a suddenly binding borrowing constraint as an unanticipated surprise to which economic agents did not assign some probability of occurrence, however small, in forming their optimal plans. To the contrary, the agents fear of a Sudden Stop influences critically their saving, consumption, investment, current account, and portfolio decisions. It is also worth noting that all four applications yield large, nonlinear real effects relying only on credit-market imperfections without recourse to nominal rigidities or multiplicity of equilibria driven by exogenous shifts in expectations. 
The limitations of the four applications suggest two interesting agendas for further research. One relates to exploring the policy implications of the models. Most of the proposals under consideration for reforming the facilities available to a country in crisis through international financial organizations are based on the notion that macroeconomic models can be counted on to determine "sustainable" current account and debt positions, as well as asset prices that reflect "normal" market conditions vis-à-vis prices that reflect "imperfections" resulting from moral hazard, informational frictions, or other distortions (see, for example, Calvo (2002) and Lerrick and Meltzer (2001)). Clearly, developing dependable quantitative models to perform these tasks hinges on making progress in producing useful quantitative models of Sudden Stops.

The second agenda for further research would address several of the weaknesses of the applications reviewed in this paper. The ability-to-pay applications did not fully enforce ability to pay criteria and were not concerned with maintaining the borrowers' incentives to repay their debt even if they were able to repay. It would be interesting to develop quantitative models that incorporate both of these features. The applications also did not take into account credit frictions affecting firms directly or foreign traders in the global credit market, differences in the maturity of debt contracts, interactions of the credit frictions with government-issued debt instruments and monetary distortions, and the endogenous determination of coefficients driving margin and liquidity requirements. Clearly, much remains to be done in the area of developing quantitative models for explaining the dynamics of small open economies in the globalized world economy of this new century. 


\section{References}

Aghion, Philippe, Philippe Bacchetta, and Abhijit Banerjee, (2000), "Currency Crises and Monetary Policy with Credit Constraints," mimeo, Department of Economics, Harvard University.

Aiyagari, S. Rao (1993) "Explaining Financial Market Facts: The Importance of Incomplete Markets and Transactions Costs," Federal Reserve Bank of Minneapolis Quarterly Review 17, 17-31.

and Mark Gertler (1999), "Overreaction of Asset Prices in General Equilibrium," Review of Economic Dynamics.

Alvarez, Fernando and Urban J. Jermann (2000) "Efficiency, Equilibrium, and Asset Pricing with Risk of Default." Econometrica, v. 68(4), 775-798.

Arellano, Cristina (2002) "Dollarization and Borrowing Limits," mimeo, Department of Economics, Duke University.

Atkeson, Andrew (1991), "International Lending with Moral Hazard and Risk of Repudiation," Econometrica, v. 59 (4), 1069-89.

Auenhaimer, Leonardo and Roberto Garcia-Saltos (2000), "International Debt and the Price of Domestic Assets, ” IMF Working Paper 00/177

Bernanke, Ben and Mark Gertler (1995), "Inside the Black Box: The Credit Channel of Monetary Policy Transmission," Journal of Economic Perspectives , Fall 27-48.

Bernanke, Ben, Gertler, Mark and Simon Girlchrist (1998), "The Financial Accelerator in a Quantitative Business Cycle Framework." NBER Working Paper No. 6455, National Bureau of Economic Research, Cambridge: MA.

Bulow, Jeremy and Kenneth Rogoff (1989), “A Constant Recontracting Model of Sovereign Debt," Journal of Political Economy, v. 97, 155-178.

, and Kenneth Rogoff, (1989), "Sovereign Debt: Is to Forgive to Forget?" American Economic Review, v.79, 43-50.

Caballero, Ricardo J. ad Arvind Krishnamurthy (2001), "International and Domestic Collateral Constraints in a Model of Emerging Market Crises," Journal of Monetary Economics, v.48, 513548.

Calvo, Guillermo A. (2002), "Globalization Hazard and Delayed Reform in Emerging Markets," mimeo, Center for International Economics, Department of Economics, University of Maryland. 
(2000), "Balance of Payments Crises in Emerging Markets: Large Capital Inflows and Sovereign Governments.” In Currency Crises, Paul Krugman ed. Chicago: University of Chicago Press.

(1986), “Temporary Stabilization: Predetermined Exchange Rates,” Journal of Political Economy 94, 1319-29.

(1998), "Capital Flows and Capital-Market Crises: The Simple Economics of Sudden

Stops," Journal of Applied Economics, v.1, pp 35-54.

, and Allan Drazen (1998), "Uncertain Duration of Reform: Dynamic Implications,"

Macroeconomic Dynamics.

, and Carmen M. Reinhart (1999), "When Capital Inflows come to a Sudden Stop:

Consequences and Policy Options," mimeo, Center for International Economics, Department of Economics, University of Maryland.

, and Enrique G. Mendoza (1996), "Mexico's Balance of Payments Crises: A Chronicle of a Death Foretold,” Journal of International Economics, v. 41, pp. 235-264.

and Enrique G. Mendoza (2000a), "Capital-Market Crises and Economics Collapse in Emerging Markets: An Informational-Frictions Approach," American Economic Review: Papers and Proceedings, May.

, and Enrique G. Mendoza (2000b), "Rational Contagion and the Globalization of Securities Markets," Journal of International Economics, v.51.

Carroll, Christopher D. (2000), "A Theory of the Consumption Function, With and Without Liquidity Constraints," mimeo, Department of Economics, Johns Hopkins University.

Correira, Isabel , J. Neves and Sergio Rebelo (1995), "Business Cycles in a Small Open Economy," European Economic Review, 39: 1089-1113, 1995.

Cespedes, Luis, Roberto Chang and Andres Velasco (2000), "Balance Sheets and Exchange Rate Policy," mimeo, Department of Economics, New York University.

Christiano, Lawrence J., Christopher Gust and Jorge Roldos (2000), "Monetary Policy in an International Financial Crisis," mimeo, Research Department, International Monetary Fund, Washington DC.

Chari, V.V. and Patrick Kehoe (2000), "Financial Crises as Herds," Federal Reserve Bank of Minneapolis, Research Department.

Cole, Harold and Timothy Kehoe (2000), "Self-Fulfilling Debt Crises," Review of Economic Studies, vol 67(1), no. 230, 91-116. 
Eaton, Jonathan, and Mark Gersovitz (1981), "Debt with Potential Repudiation: Theoretical and Empirical Analysis,” Review of Economic Studies, v. XLVII, 289-309.

Eaton, Jonathan and Raquel Fernandez (1995), "Sovereign Debt," Handbook of International Economics. G. M. Grossman and K. Rogoff. Amsterdam: Elsevier, v.3 2031-2076.

Edison, Hali, Pongsak Luangaram and Marcus Miller (2000), "Asset Bubbles, Domino Effects and "Lifeboats": Elements of the East Asian Crisis," The Economic Journal, January, vol. 110.

Edwards, Sebastian, ed. (2000), Capital Flows and the Emerging Markets Economies. A National Bureau of Economic Research Conference Report. Chicago: University of Chicago Press.

Epstein Larry G. (1983), "Stationary Cardinal Utility and Optimal Growth under Uncertainty," Journal of Economic Theory, 31, 133-152.

Frankel, Jeffrey and Sebastian Edwards (2002), Preventing Currency Crises in Emerging Markets. A National Bureau of Economic Research Conference Report. Chicago: University of Chicago Press, forthcoming.

Fisher, Irving (1993), “The Debt-Deflation Theory of Great Depressions,” Econometrica 1, 33757.

Greenwood, Jeremy, Zvi Hercowitz and Gregory W. Huffman (1988), "Investment, Capacity Utilization and the Real Business Cycle", American Economic Review, June.

Fisher, Irving (1933), “The Debt-Deflation Theory of Great Depressions," Econometrica 1, 33757.

Hamann, Franz (2002), "Sovereign Risk and Macroeconomic Volatility," mimeo, Department of Economics, North Carolina State University.

Heaton, John and Deborah Lucas (1996), "Evaluating the Effects of Incomplete Markets on Risk Sharing and Asset Pricing," Journal of Political Economy, 104, no. 3, 443-487.

International Monetary Fund (1999), International Capital Markets, September, International Monetary Fund, Washington:DC.

Izquierdo, Alejandro (2000) "Credit Constraints, and the Asymmetric Behavior of Asset Prices and Output under External Shocks," mimeo, The World Bank. June.

Judd, Kenneth L., Felix Kubler and Karl Schmedders (2000), "Computational Methods for Dynamic Equilibria with Heterogeneous Agents," mimeo, Hoover Institution.

Kaminsky, Graciela L. and Carmen M. Reinhart (2000), “On Crises, Contagion, and Confusion,” Journal of International Economics, v. 51, pp.145-168. 
Kehoe, Patrick and Fabrizio Perri (2002) "International Business Cycles with Endogenous Incomplete Markets," Econometrica, forthcoming.

Kehoe, Timothy J. and David K. Levine (1993), "Debt-Constrained Asset Markets.” Review of Economic Studies 60 868-88.

Kiyotaki, Nobuhiro and John Moore (1997), "Credit Cycles," Journal of Political Economy, v.105, 211-248.

Kletzer, Kenneth M. and Brian D. Wright (2000), "Sovereign Debt as Intertermporal Barter," American Economic Review. 90(3), 621-639.

Kocherlakota, Narayana (1996) "Implications of Efficient Risk Sharing without Commitment." Review of Economic Studies, 595-609.

Krugman, Paul ed. (2000), Currency Crises. A National Bureau of Economic Research Conference Report. Chicago: University of Chicago Press.

Krusell, Per and Anthony A. Smith Jr. (1997), "Income and Wealth Heterogeneity, Portfolio Choice, and Equilibrium Asset Returns," Macroeconomic Dynamics, 1, 387-422.

Lerrick, Adam, and Allan H. Meltzer (2001), "Blueprint for and International Lender of Last Resort," mimeo, Carnegie Mellon University.

Lucas, Deborah J. (1994) "Asset Pricing with Undiversifiable Income Risk and Short Sales Constraints," Journal of Monetary Economics, 34, 325-41.

Lucas, Robert E., Jr. (1987), Models of Business Cycles, Basil-Blackwell, New York: NY.

Ljungqvist, Lars , and Thomas J. Sargent (2000), Recursive Macroeconomic Theory, Boston: MIT Press.

Mendoza, Enrique G. (2002), "Credit, Prices, and Crashes: Business Cycles with a Sudden Stop." In Preventing Currency Crises in Emerging Markets, Frankel, Jeffrey and Sebastian Edwards eds. Chicago: University of Chicago Press, forthcoming.

(2001), "The Benefits of Dollarization when Stabilization Policy Lacks Credibility and Financial Markets are Imperfect," Journal of Money, Credit and Banking, forthcoming.

(1995), "The Terms of Trade, The Real Exchange Rate and Economic Fluctuations," International Economic Review, v. 36, 101-137, February.

(1991a), "Real Business Cycles in a Small Open Economy," American Economic Review, v. $81,797-818$, September. 
(1991b), "Capital Controls and the Gains from Trade in a Business Cycle Model of a Small Open Economy," IMF Staff Papers, September, v. 38, 480-505.

, and Katherine A. Smith (2001), "Margin Calls, Trading Costs and Asset Prices in Emerging Markets: the Financial Mechanics of the 'Sudden Stops' Phenomenon," mimeo, Department of Economics, Duke University.

, and Martin Uribe (2001), "Devaluation Risk and the Business Cycle Implications of Exchange Rate Management," Carnegie-Rochester Conference Series on Public Policy, 53.

Milesi-Ferreti, Gian Maria, and Assaf Razin (2000), "Current Account Reversals and Currency Crises:Empirical Regularities." In Currency Crises, Paul Krugram ed. Chicago: University of Chicago Press.

Neumeyer, Pablo and Fabrizio Perri (2001), "Business Cycles in Emerging Economies: The Role of Interest Rates," mimeo, Department of Economics, New York University.

Obstfeld, Maurice (1981), "Macroeconomic Policy, Exchange Rate Dynamics, and Optimal Asset Accumulation," Journal of Political Economy, v.89, 1142-61.

Oviedo, Pedro (2002), "Business Cycles in Small Economies with a Banking Sector," mimeo, North Carolina State University.

Paasche, Bernhard (2001), "Credit Constraints and International Financial Crises," Journal of Monetary Economics, v.28, 623-650.

Parsley, David (2001), “Accounting for Real Exchange Rate Changes in East Asia,” Hong Kong Institute of Monetary Research working Paper No. 6/2001, July.

Reif, Tania (2001), "The 'Real' Side of Currency Crises," mimeo, Columbia University.

Schmitt-Grohe, Stephanie and Martin Uribe (2001), "Closing Small Open Economy Models," mimeo, Department of Economics, University of Penssylvania.

Schneider, Martin and Aron Tornell (1999), "Lending Booms, Asset Price Inflation and Soft Landings," mimeo, Department of Economics, University of Rochester.

Wright, Mark (2001), "Reputations and Sovereign Debt," mimeo, Department of Economics, MIT.

Zhang, Harold (1997) "Endogenous Borrowing Constraints with Incomplete Markets." The Journal of Finance, December . 
Table 1. Parameter Values for the Calibrated Deterministic Stationary State

\begin{tabular}{|c|c|c|c|c|c|}
\hline Technology: & & Fiscal policy: & & Credit market: & \\
\hline$\alpha$ & 0.364 & $\tau$ & 0.079 & $R$ & 1.016 \\
\hline$A$ & 1.958 & T traded & -0.139 & $\varphi$ & 0.740 \\
\hline$Y T$ & 1.000 & $T$ nontraded & 0.119 & $b / Y$ & -0.350 \\
\hline Preferences: & & $\underline{\text { National accoun }}$ & & & \\
\hline$\beta$ & 0.027 & $C / Y$ & 0.684 & $C T / Y T$ & 0.665 \\
\hline$\delta$ & 2.000 & $I / Y$ & 0.217 & $G T / Y T$ & 0.017 \\
\hline$\eta$ & 0.316 & $G / Y$ & 0.092 & $I T / Y T$ & 0.323 \\
\hline$\omega$ & 0.342 & $N X / Y$ & -0.001 & $C N / Y N$ & 0.708 \\
\hline \multirow[t]{2}{*}{$\sigma$} & 2.000 & $Y T / Y N$ & 0.648 & $G N / Y N$ & 0.141 \\
\hline & & & & $I N / Y N$ & 0.151 \\
\hline
\end{tabular}


Table 2. Business Cycle Comovements in the Limiting Distribution of Model Economies

\begin{tabular}{|c|c|c|c|c|c|}
\hline & Mean & $\begin{array}{l}\text { Standard } \\
\text { Deviation }\end{array}$ & $\begin{array}{l}\text { Standard Dev. } \\
\text { relative to GDP of } \\
\text { nontradables }\end{array}$ & $\begin{array}{c}\text { First-order } \\
\text { Autocorrelation }\end{array}$ & $\frac{\text { Correlation with }}{\text { GDP }}$ \\
\hline \multicolumn{6}{|c|}{ Economy with Perfect Credit Markets } \\
\hline Net foreign assets & -0.097 & 0.883 & 14.274 & 0.999 & 0.321 \\
\hline GDP in units of tradables & 2.598 & 7.307 & 1.829 & 0.931 & 1.000 \\
\hline Tradables GDP & 1.000 & 3.368 & 0.843 & 0.553 & 0.387 \\
\hline Nontradables GDP & 1.548 & 3.995 & 1.000 & 0.633 & 0.387 \\
\hline Labor & 0.524 & 5.003 & 1.252 & 0.928 & 0.976 \\
\hline Consumption & 0.924 & 6.254 & 1.565 & 0.839 & 0.823 \\
\hline Consumption of tradables & 0.683 & 10.162 & 2.544 & 0.934 & 0.996 \\
\hline Consumption of nontradables & 1.097 & 5.635 & 1.411 & 0.633 & 0.387 \\
\hline Net Exports & 0.002 & 25.987 & 6.504 & 0.623 & -0.025 \\
\hline Price of nontradables & 1.033 & 11.925 & 2.985 & 0.815 & 0.874 \\
\hline World real interest rate & 1.016 & 0.880 & 0.220 & 0.553 & -0.071 \\
\hline \multicolumn{6}{|c|}{ Economy with Liquidity Constraint } \\
\hline Net foreign assets & 0.258 & 0.679 & 10.957 & 0.999 & 0.313 \\
\hline GDP in units of tradables & 2.612 & 7.323 & 1.830 & 0.931 & 1.000 \\
\hline Tradables GDP & 1.000 & 3.368 & 0.842 & 0.553 & 0.391 \\
\hline Nontradables GDP & 1.549 & 4.002 & 1.000 & 0.633 & 0.391 \\
\hline Labor & 0.525 & 5.008 & 1.252 & 0.928 & 0.978 \\
\hline Consumption & 0.927 & 6.266 & 1.566 & 0.838 & 0.823 \\
\hline Consumption of tradables & 0.688 & 10.158 & 2.538 & 0.934 & 0.996 \\
\hline Consumption of nontradables & 1.098 & 5.643 & 1.410 & 0.633 & 0.391 \\
\hline Net Exports & -0.004 & 9.150 & 2.287 & 0.599 & -0.003 \\
\hline Price of nontradables & 1.041 & 11.880 & 2.969 & 0.815 & 0.874 \\
\hline World real interest rate & 1.016 & 0.880 & 0.220 & 0.553 & -0.069 \\
\hline
\end{tabular}

Note: All standard deviations are in percent of the corresponding mean, except for the one corresponding to the net foreign asset position. 
Table 3. Parameter Values for Economies with Participation Constraints

Preferences and Technology Parameters

\begin{tabular}{ll}
\hline & \\
$\beta$ & .364 \\
$\beta$ & .95 \\
$\delta$ & 2 \\
$R$ & 1.015 \\
$\sigma$ & $5 \quad$ in Experiment 1 \\
& $2 \quad$ in Experiment 2
\end{tabular}

Markov Process of Productivity Shocks

\begin{tabular}{cc}
\hline$\varepsilon^{h}=-\varepsilon^{l}=\varepsilon$ & .2 \\
$P\left(\varepsilon^{l} \mid \varepsilon^{l}\right)=P\left(\varepsilon^{h} \mid \varepsilon^{h}\right)$ & .6 \\
$P\left(\varepsilon^{l} \mid \varepsilon^{h}\right)=P\left(\varepsilon^{h} \mid \varepsilon^{l}\right)$ & .4
\end{tabular}


Figure 1. Current Account Balances in Percent of Gross Domestic Product
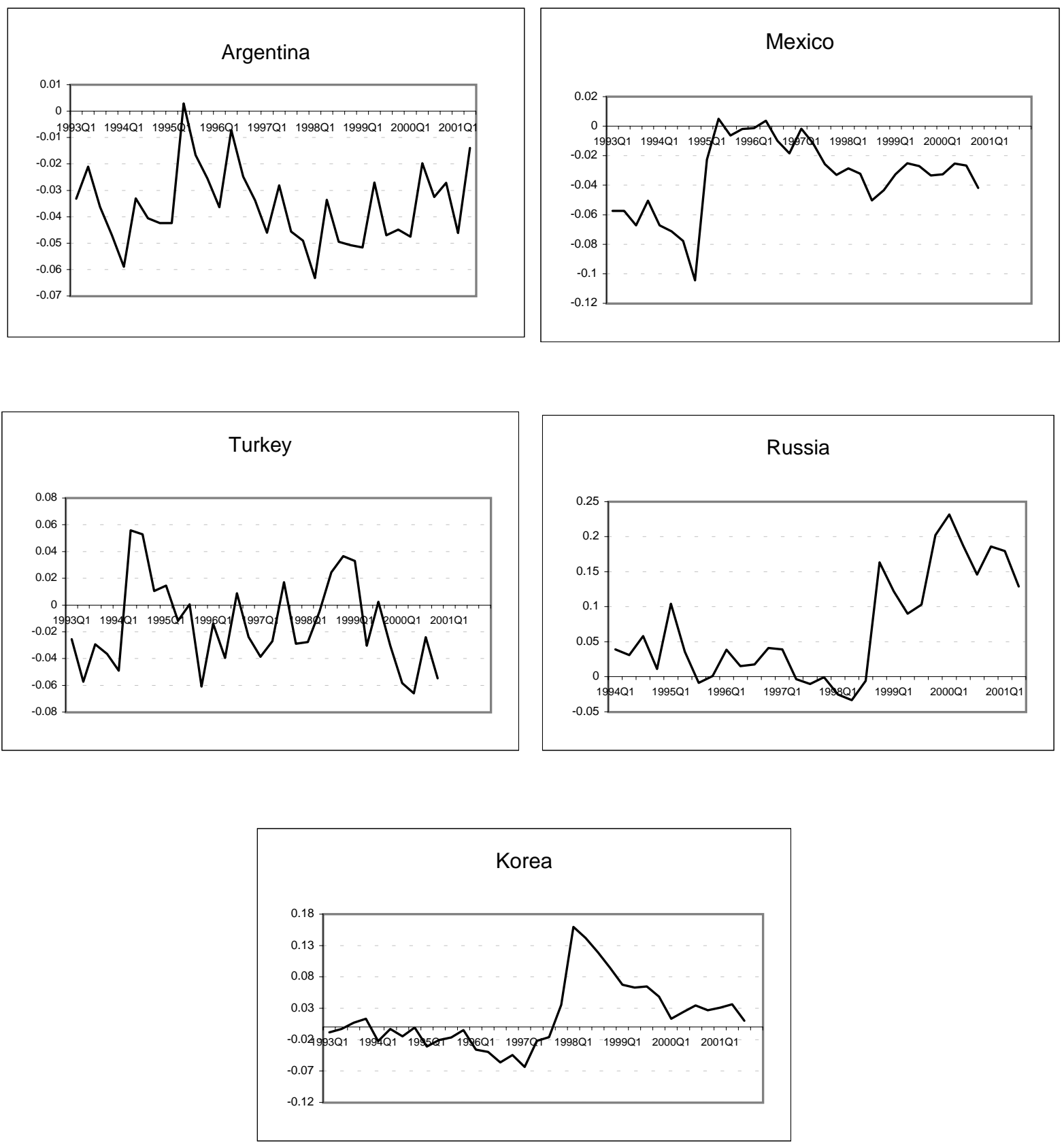

Source: International Financial Statistics, IMF 
Figure 2. Annual Growth Rates in Real Private Consumption Expenditures
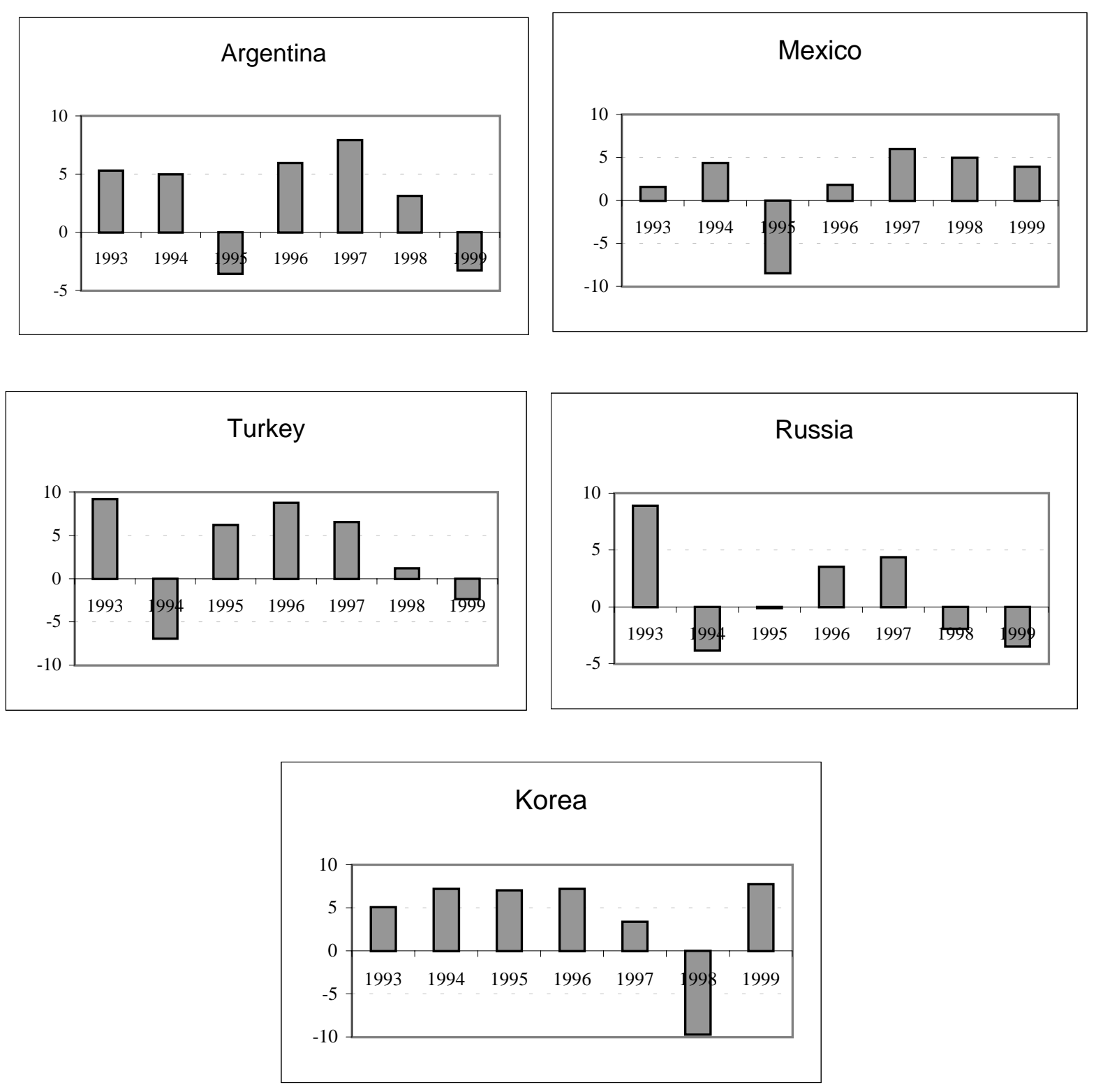

Source: World Development Indicators, World Bank 
Figure 3. Equity Prices and Country Risk
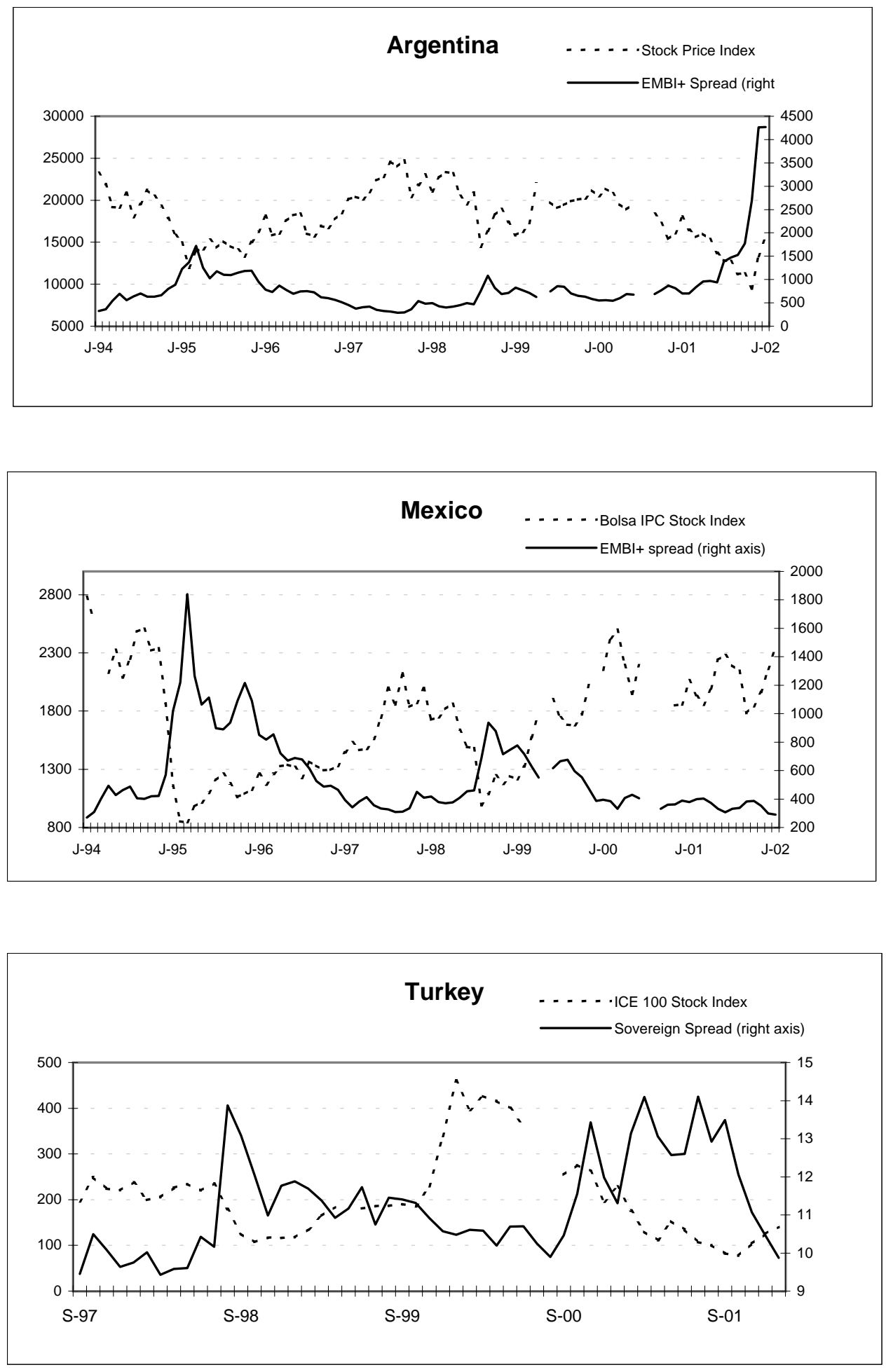
Figure 3. Equity Prices and Country Risk (continued)
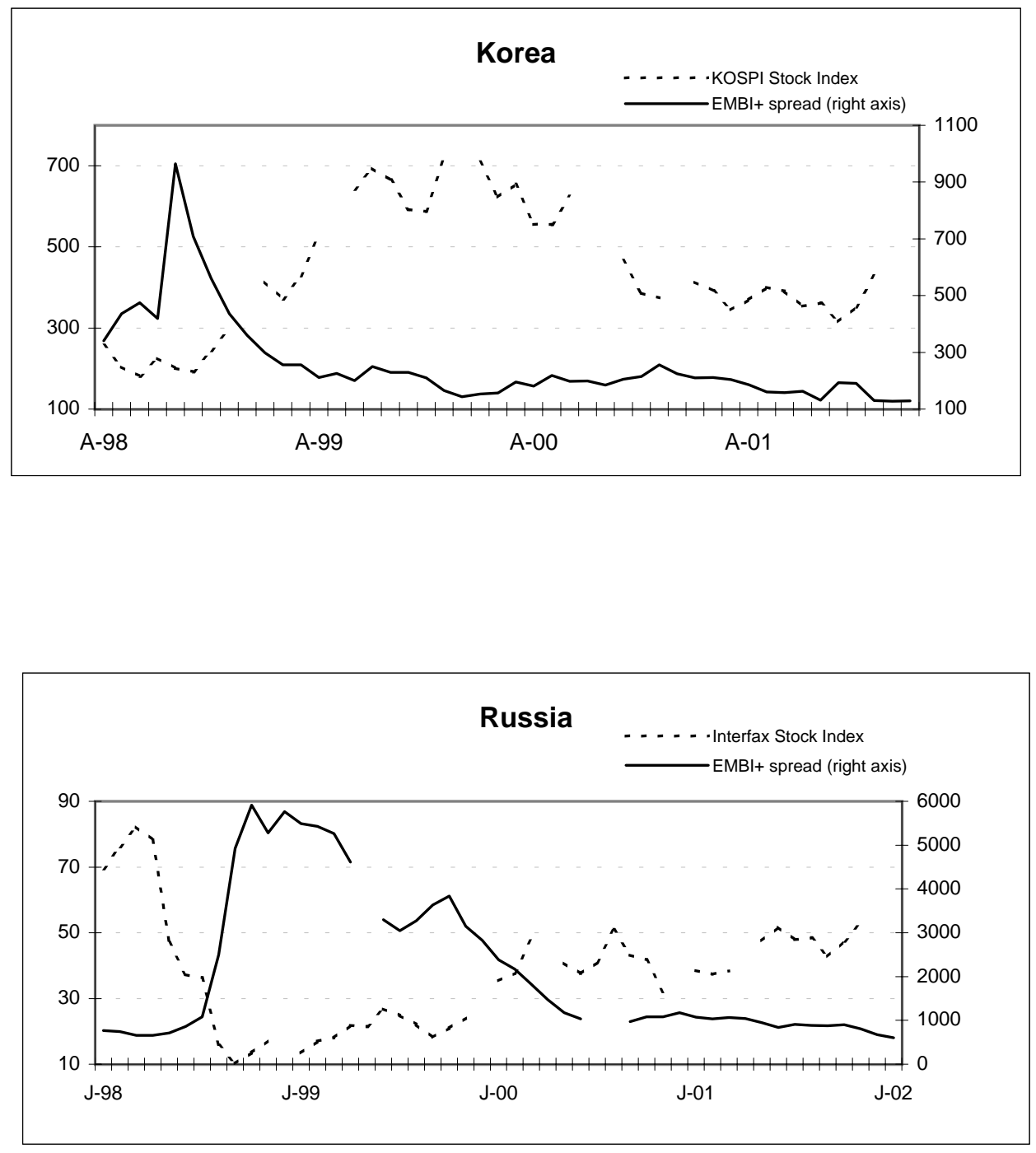

Source: JPMorgan 
Figure 4. Limiting Distributions of Net Foreign Assets

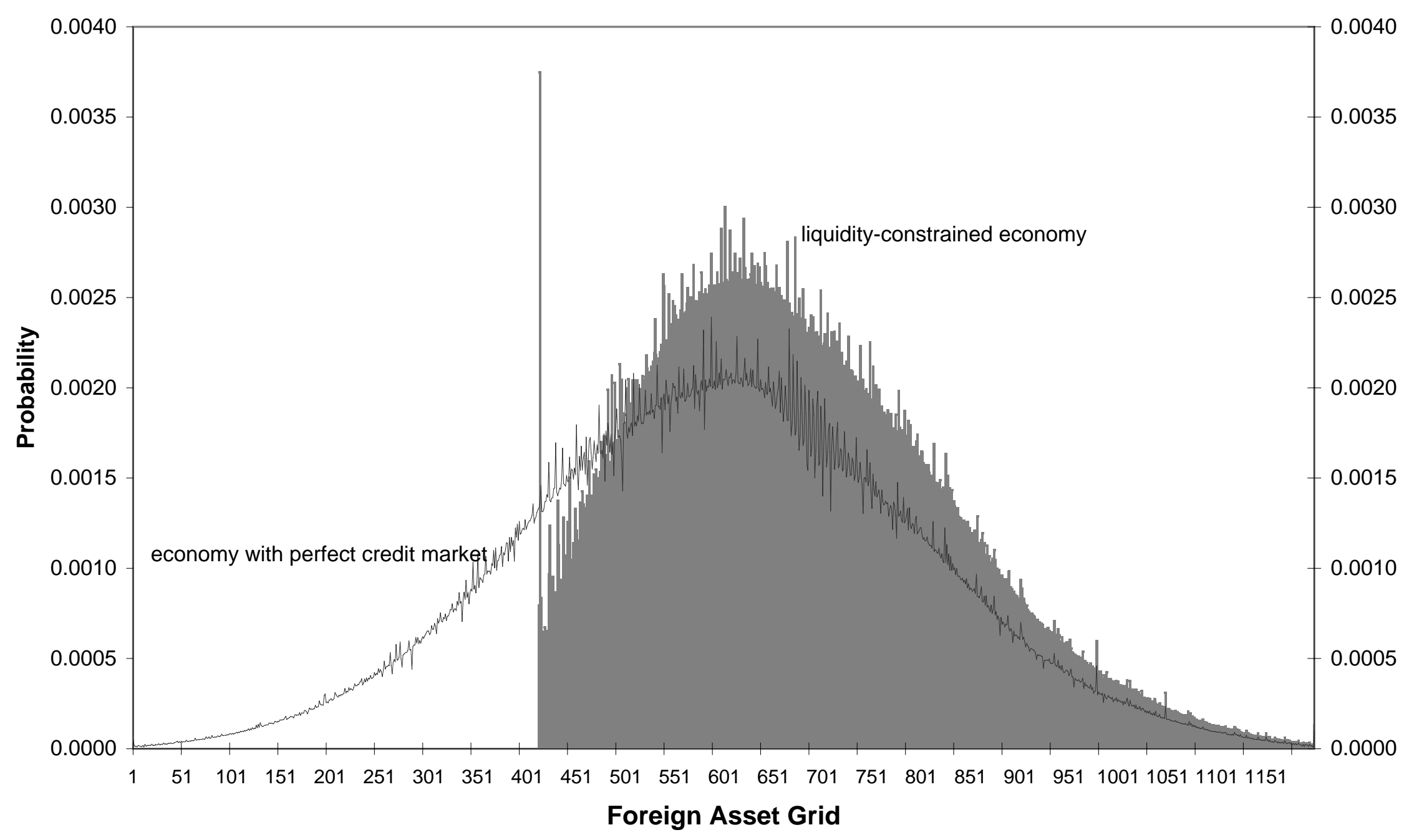


Figure 5. Impact Effects of a Shift from "Best" to "'Worst" State

(as a function of the foreign asset grid)
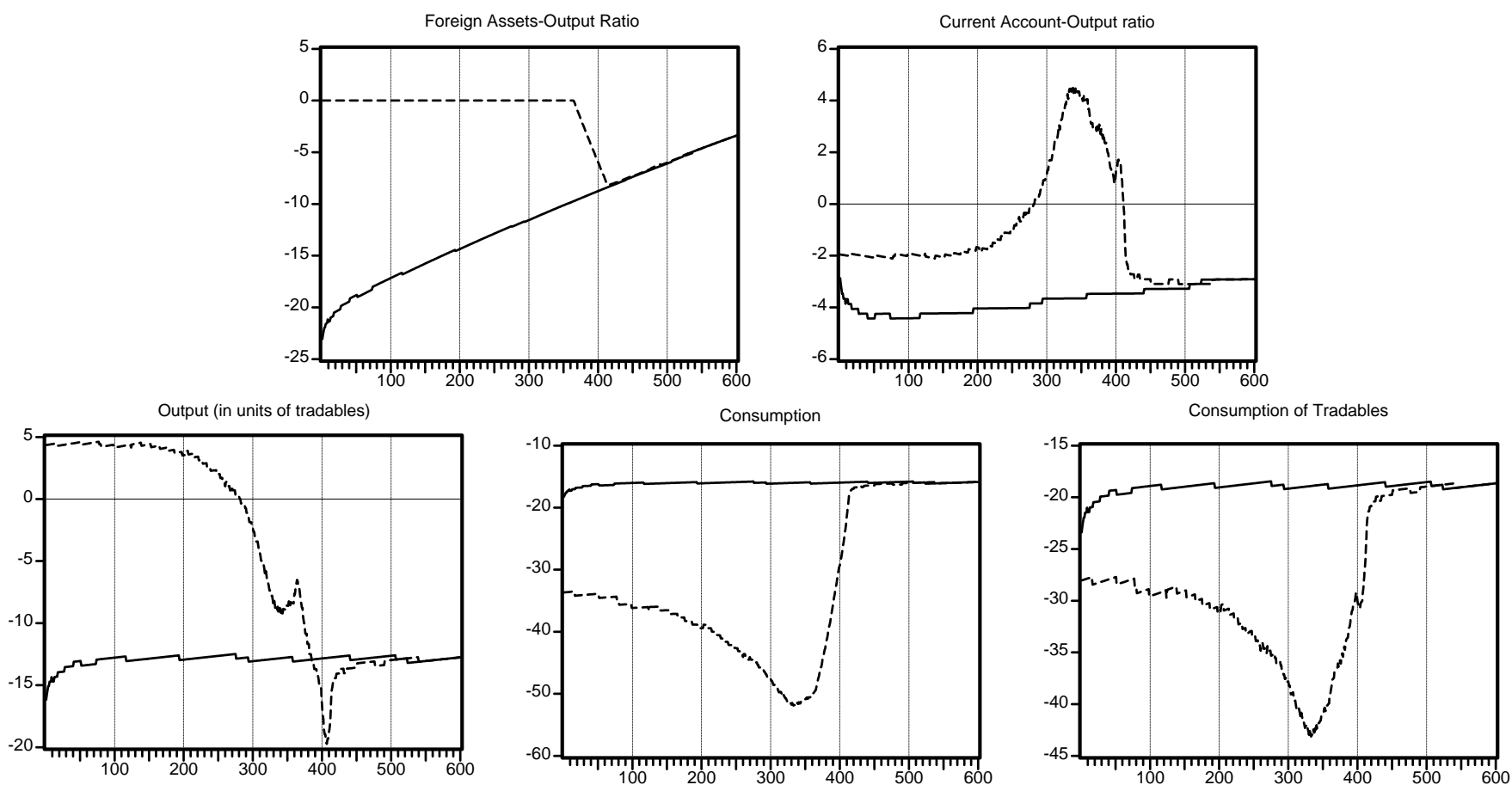

Labor
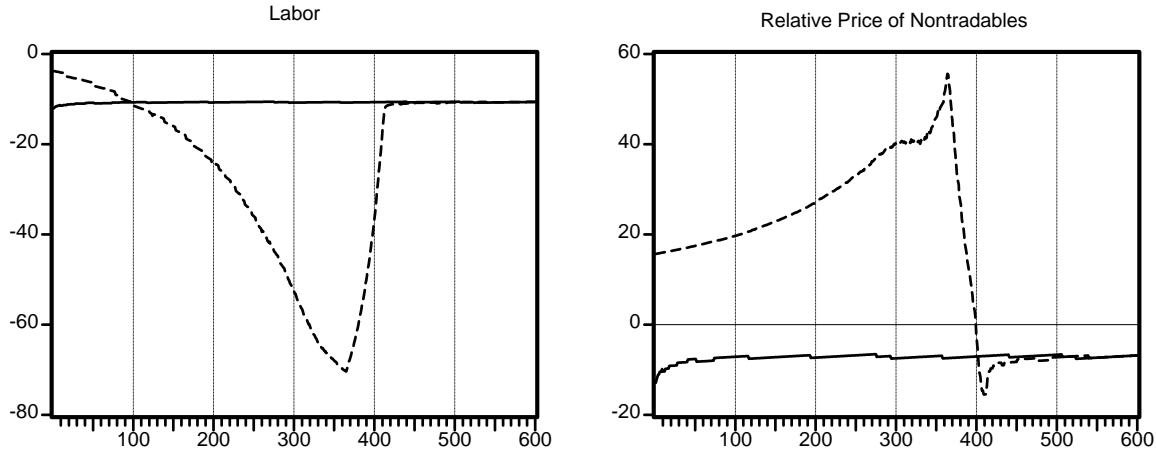

Output of Nontradables

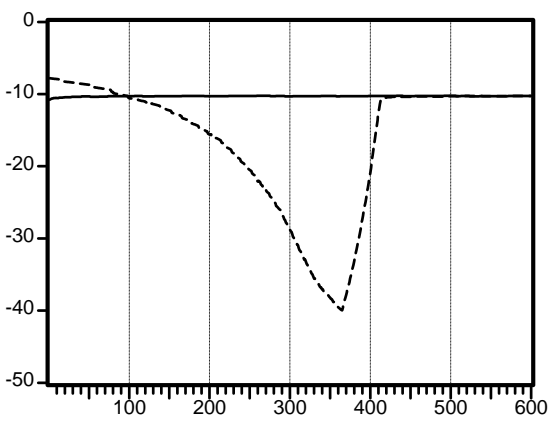

- economy w. perfect credit market --- liquidity constrained economy 
Figure 6. Transition Distributions of Net Foreign Assets in Liquidity Constrained Economy with Risk Aversion Coefficient Set at 2.0

(from largest initial debt position and random shocks in state 1)

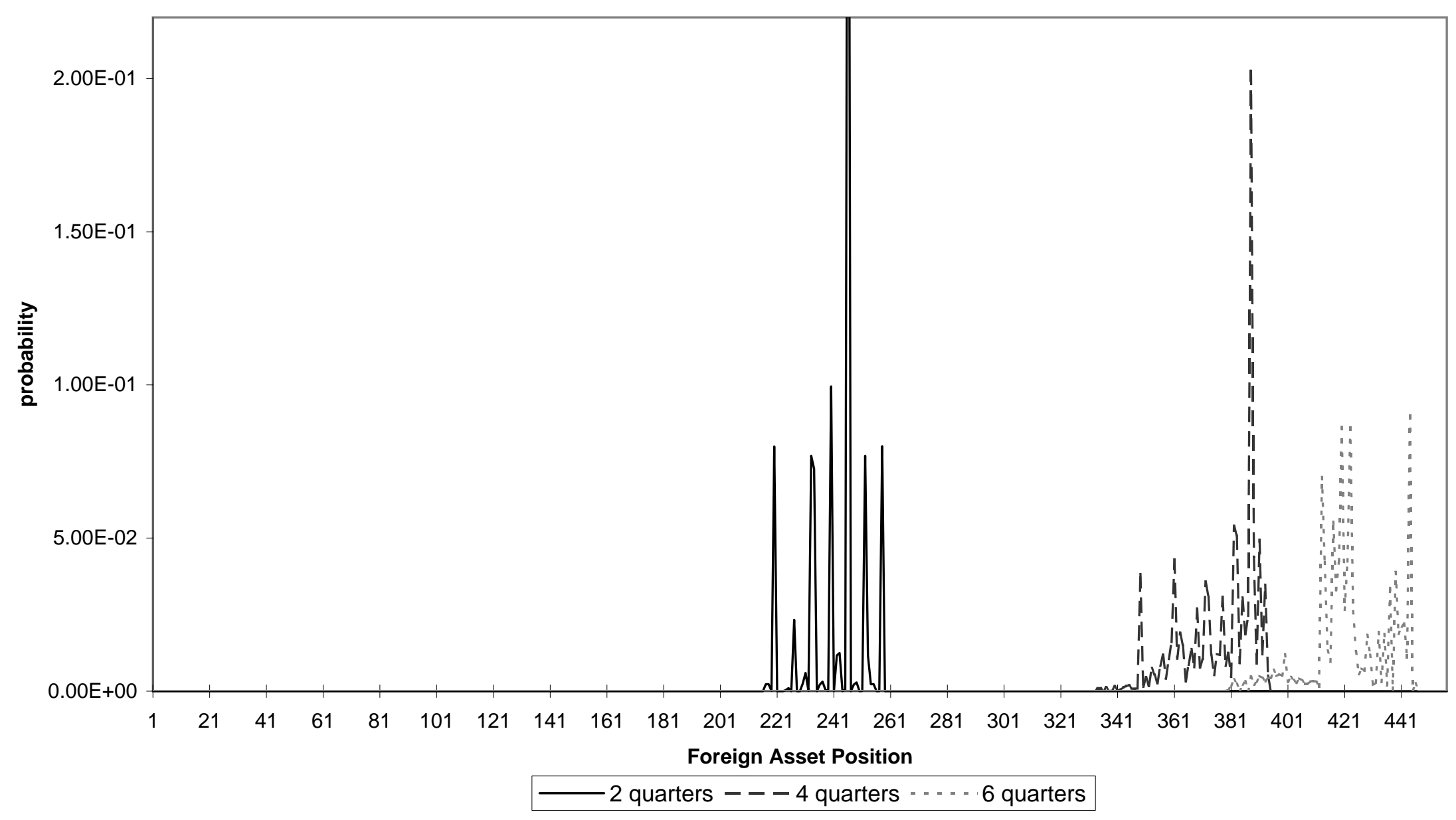


Figure 7. Transition Distributions of Net Foreign Assets in Liquidity Constrained Economy with Risk Aversion Coefficient set at 5 .

(from largest initial debt position and random shocks in state 1)

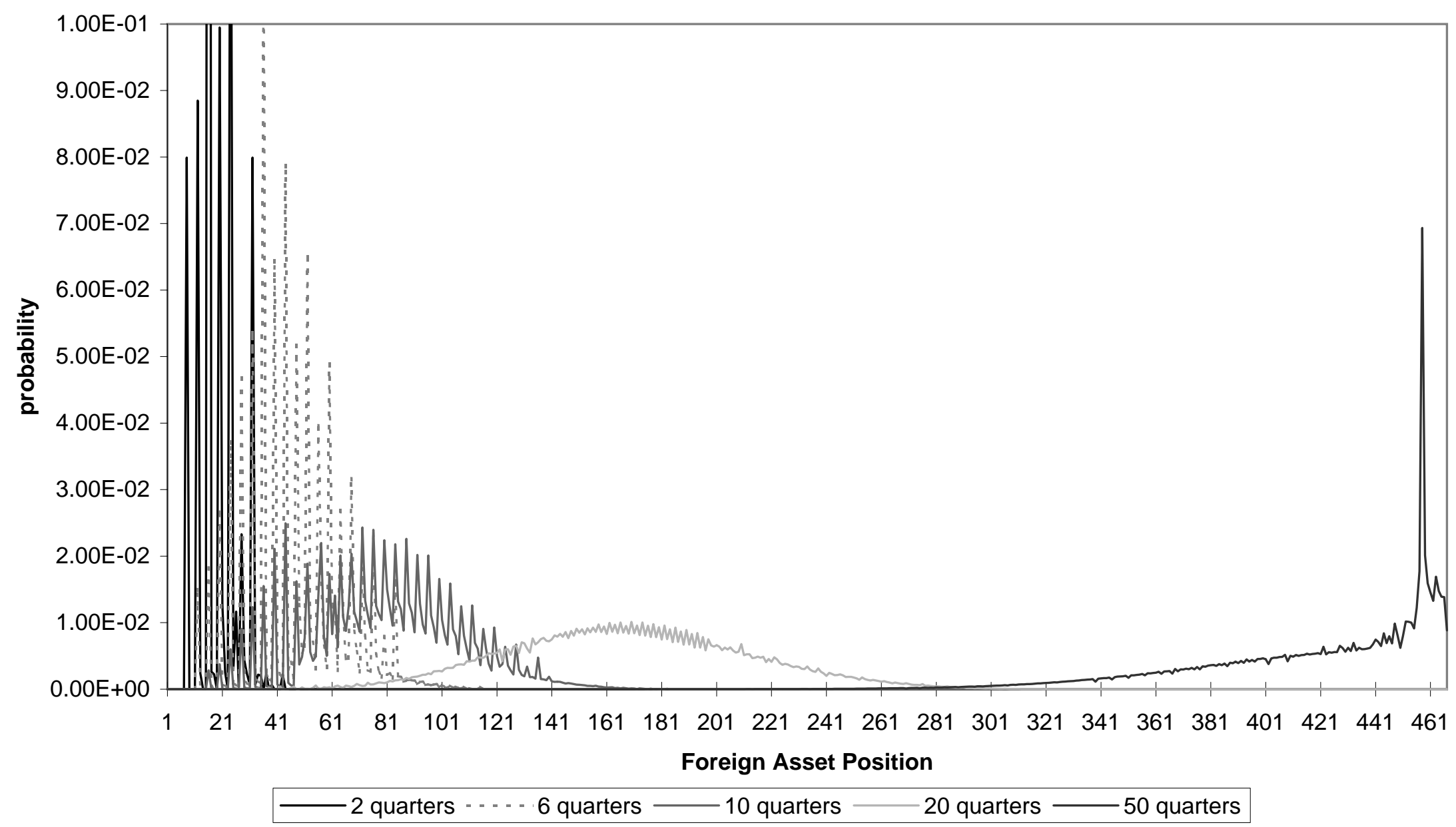


Figure 8. Foreign Bond Decision Rules for Economies with and without Margin Requirements in Low Productivity State (as functions of the $(\alpha, b)$ pairs in the discretized state space $Z$ )

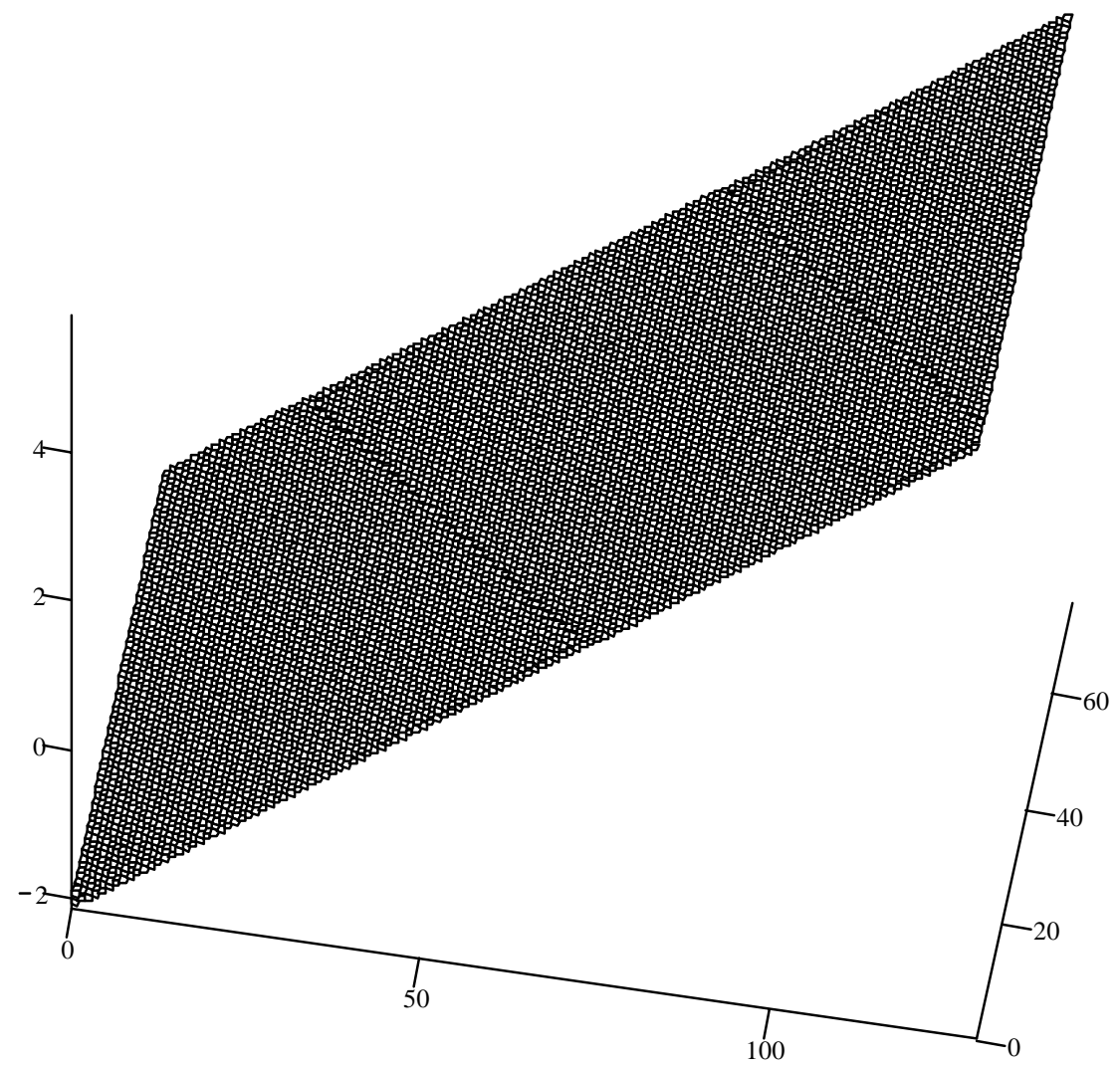

BP1 Economy with Perfect Credit Marktes

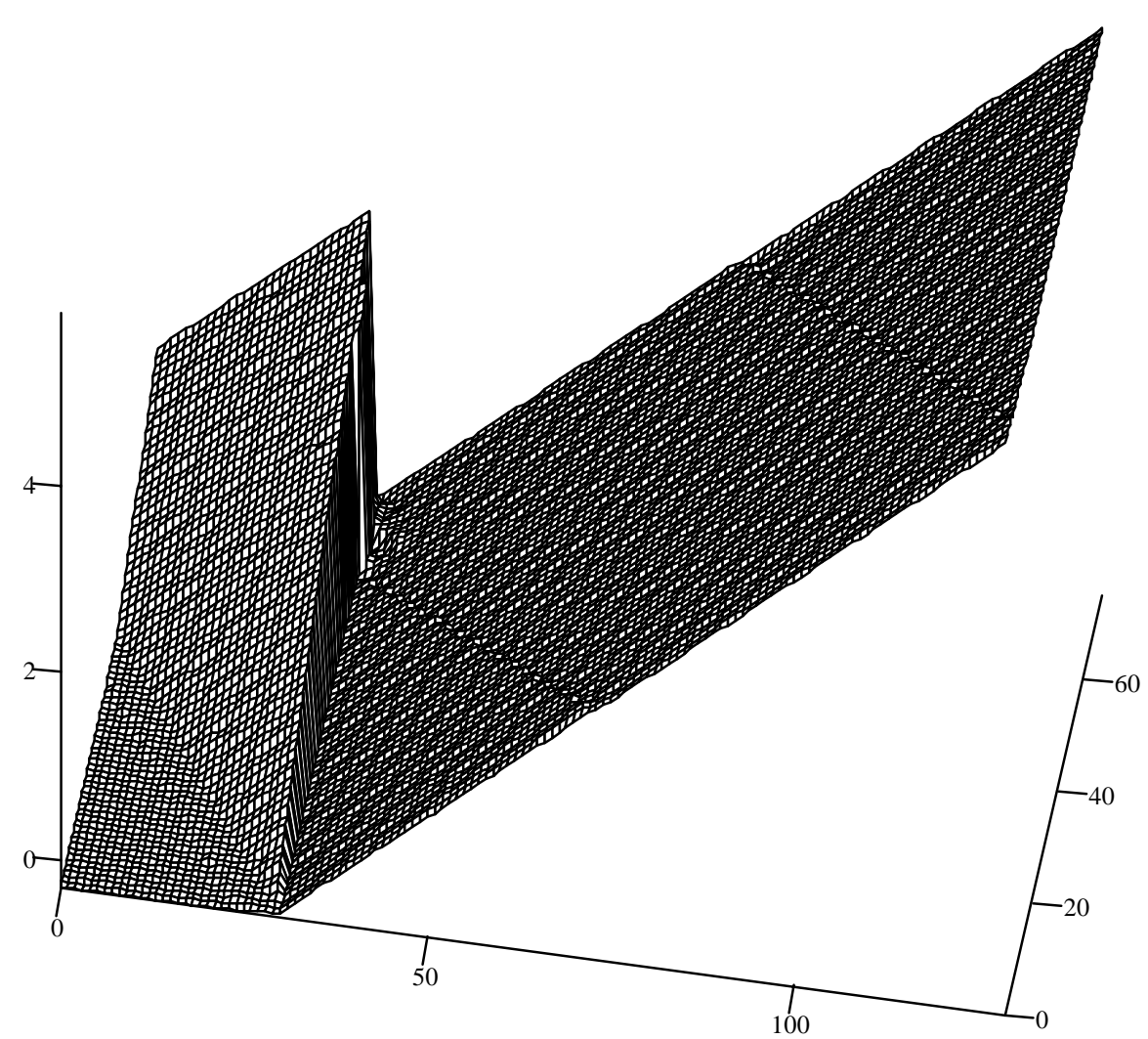

$\mathrm{BP} 1 \mathrm{~b}$ 
Figure 9. Equity Prices for Economies with and without Margin Requirements in Low Productivity State (as functions of the $(\alpha, b)$ pairs in the discretized state space $\mathrm{Z}$ )

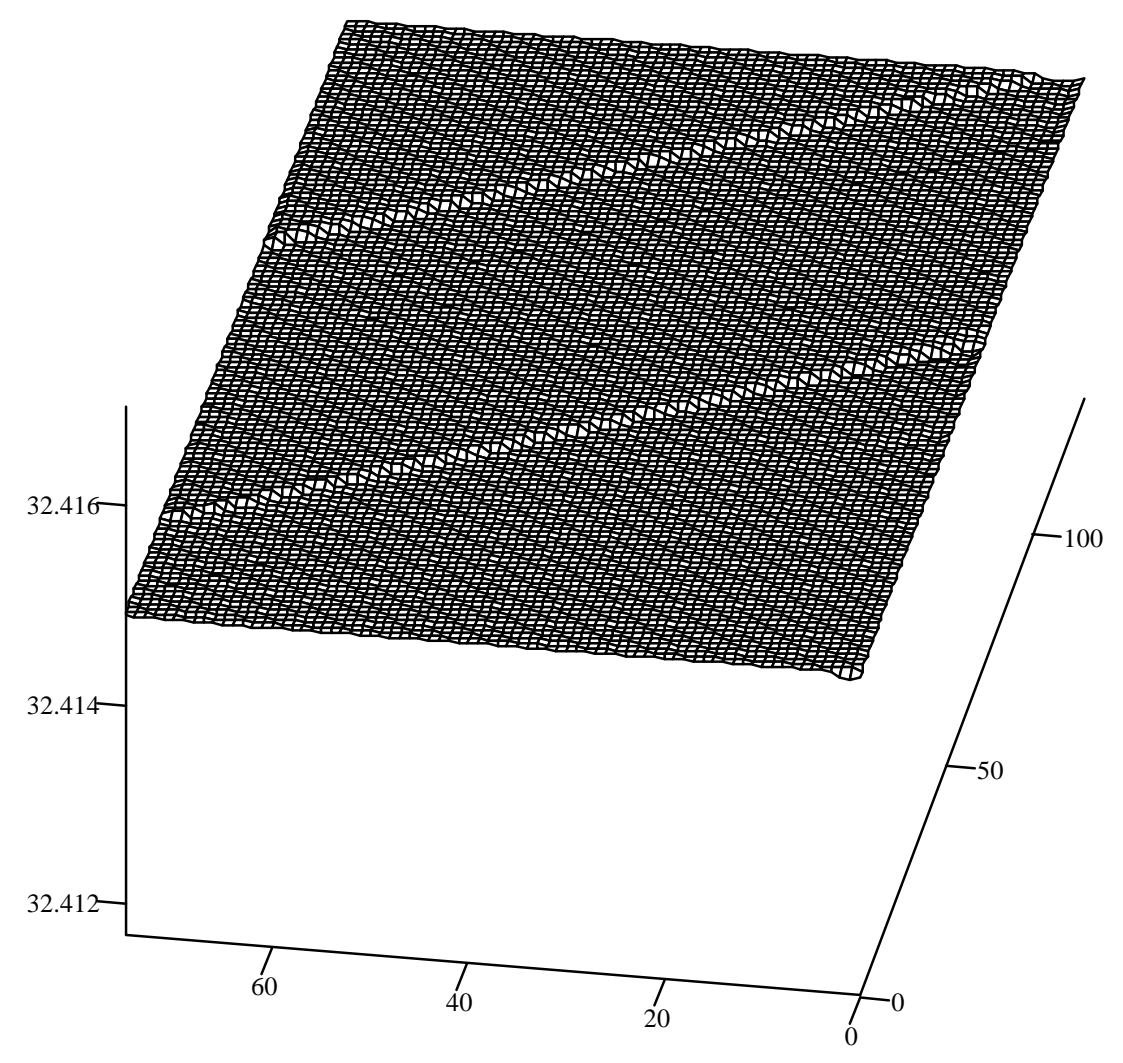

Q1

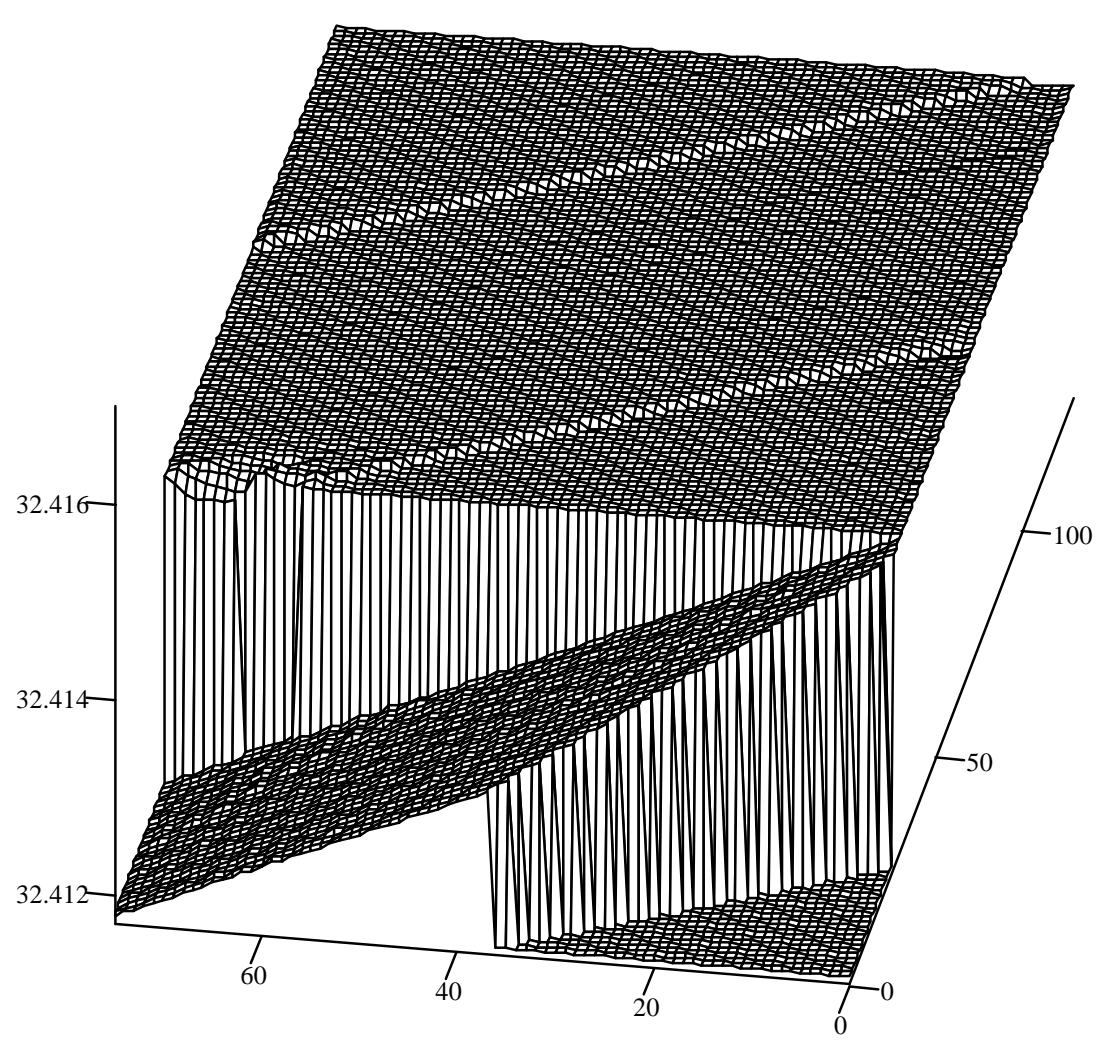

Q1b 
Figure 10. Impact Effects on Consumption in Response to a Shift from High to Low Productivity States (as functions of the $(\alpha, b)$ pairs in the discretized state space $Z$ )

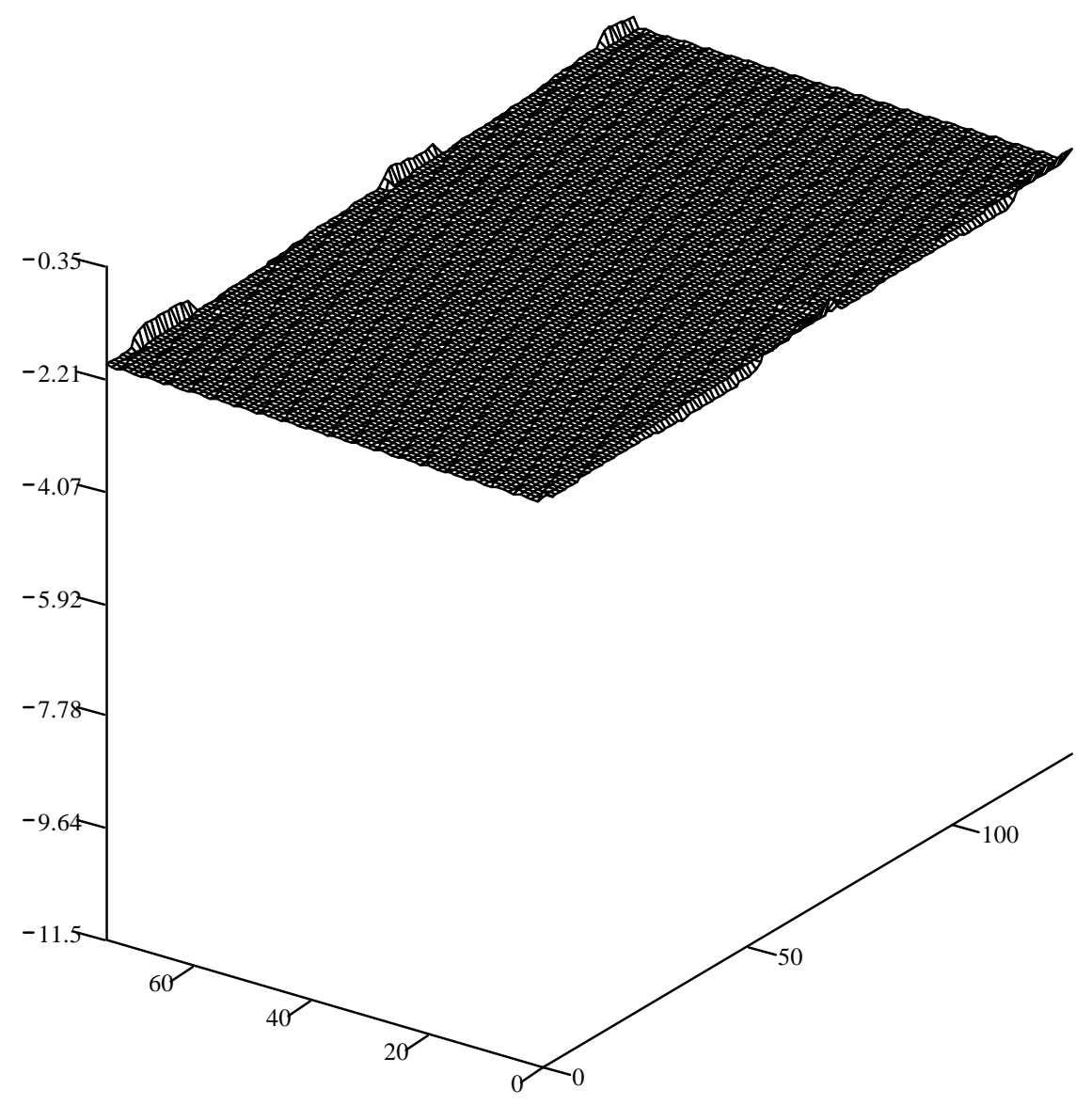

cons

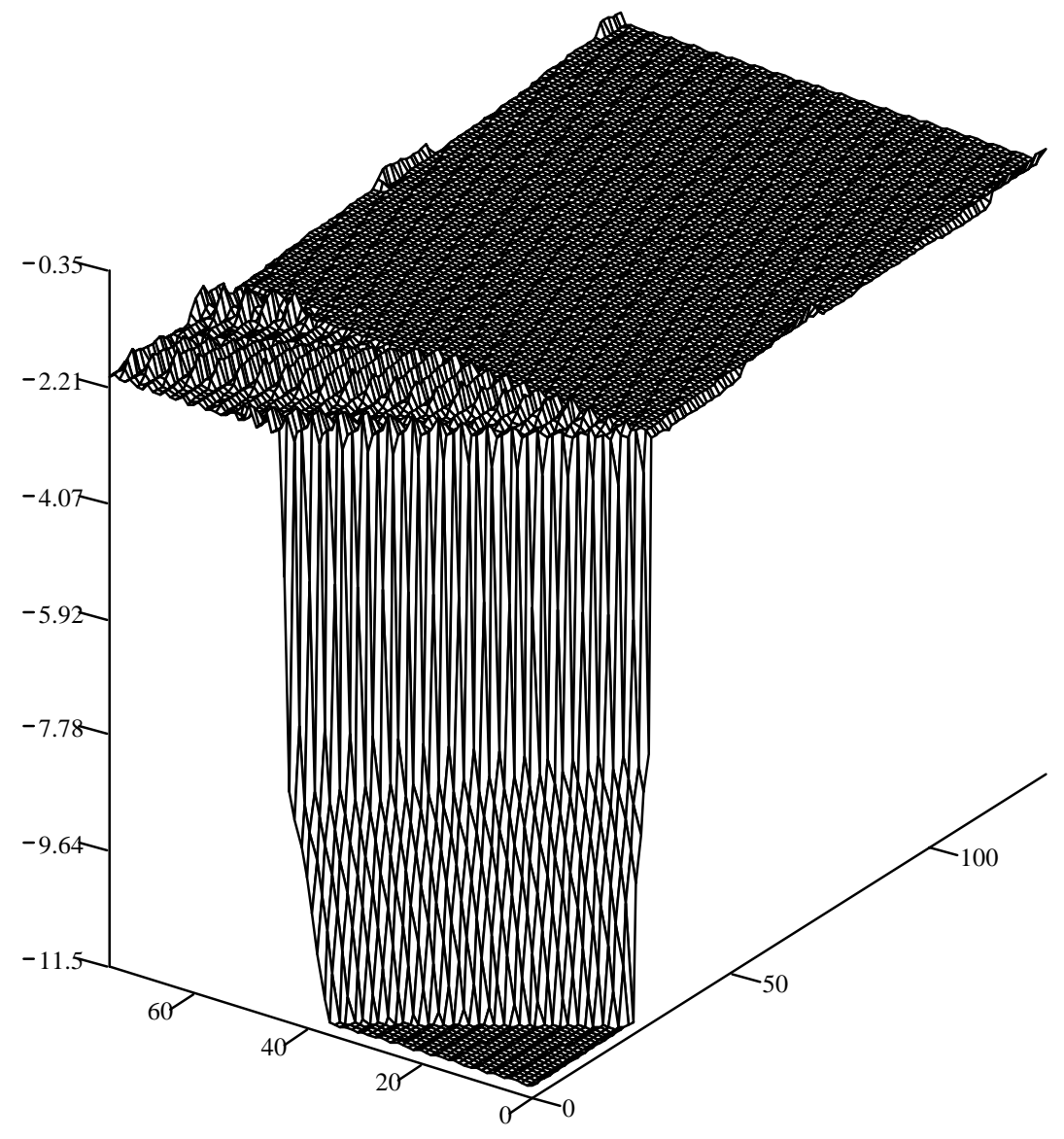

consb 
Figure 11. Impact Effects on the Current Account-Output Ratio in Response to a Shift from High to Low Productivity States (as functions of the $(\alpha, b)$ pairs in the discretized state space $\mathrm{Z}$ )

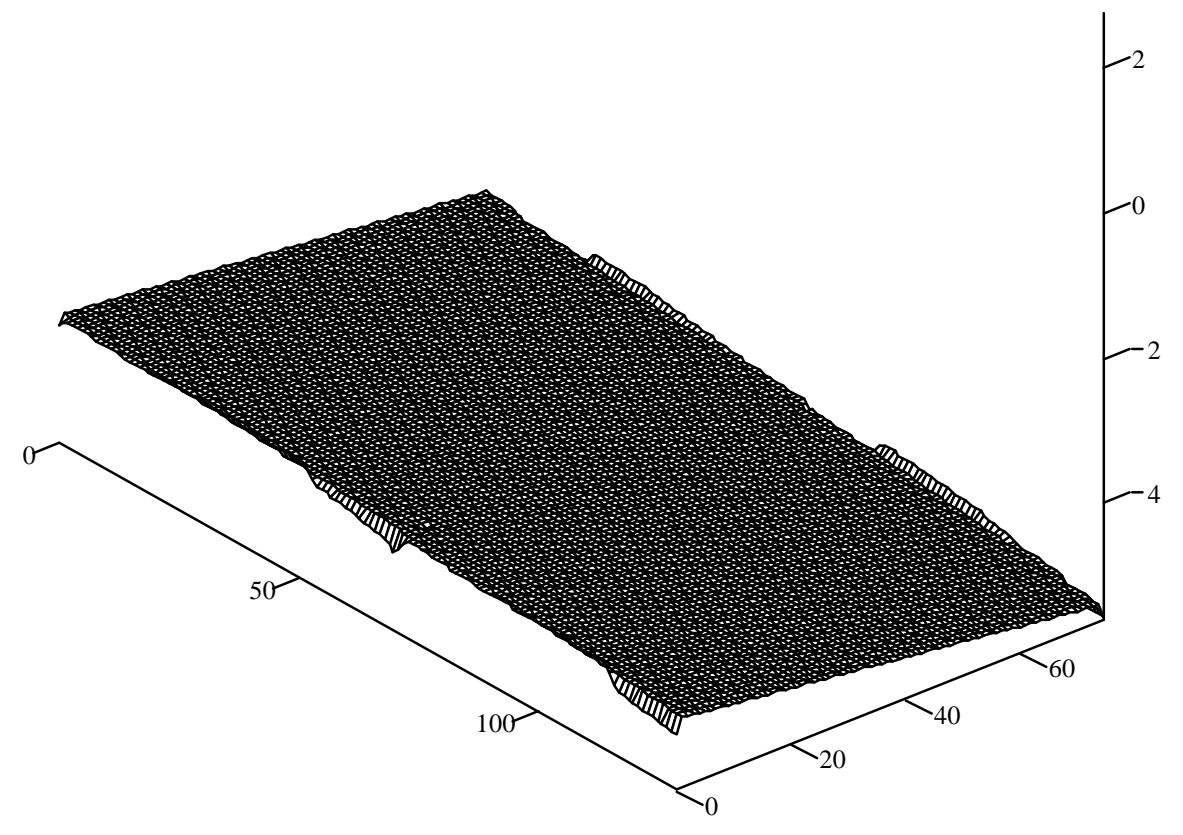

CAYIM

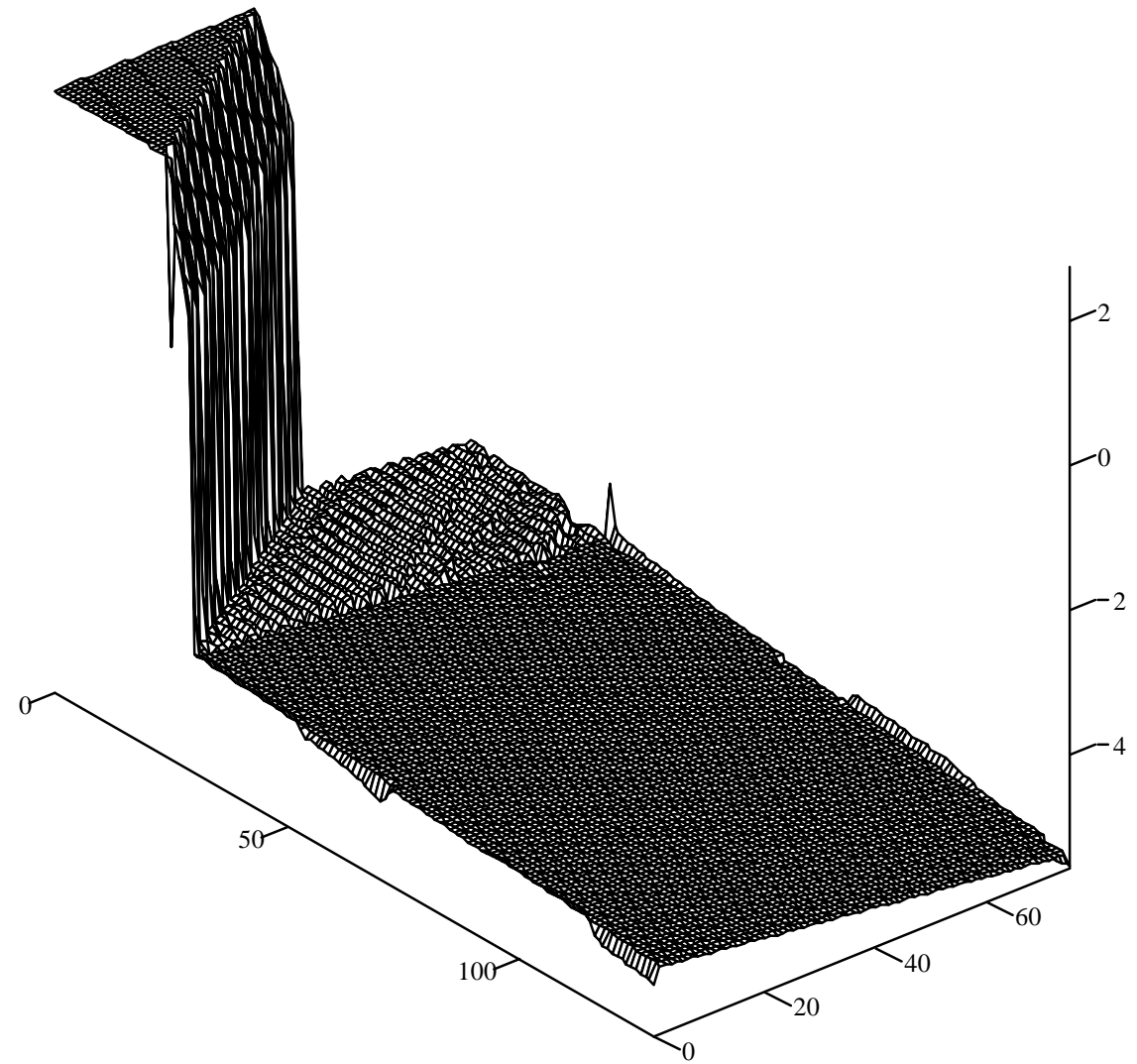

CAYIMb 
Figure 12. Lifetime Utilities as Functions of Bond Positions

Experiment $1 \quad \sigma=5$

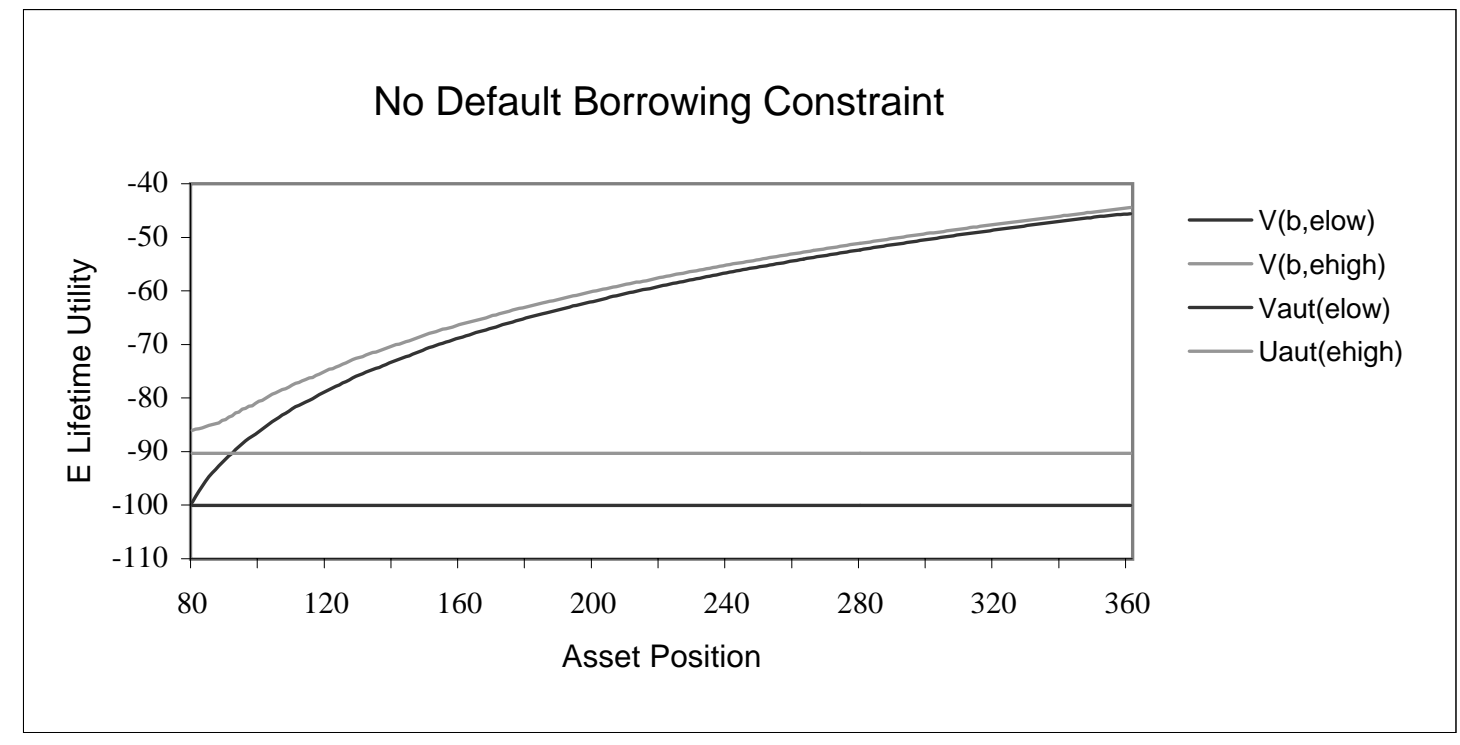

Experiment $2 \sigma=2$

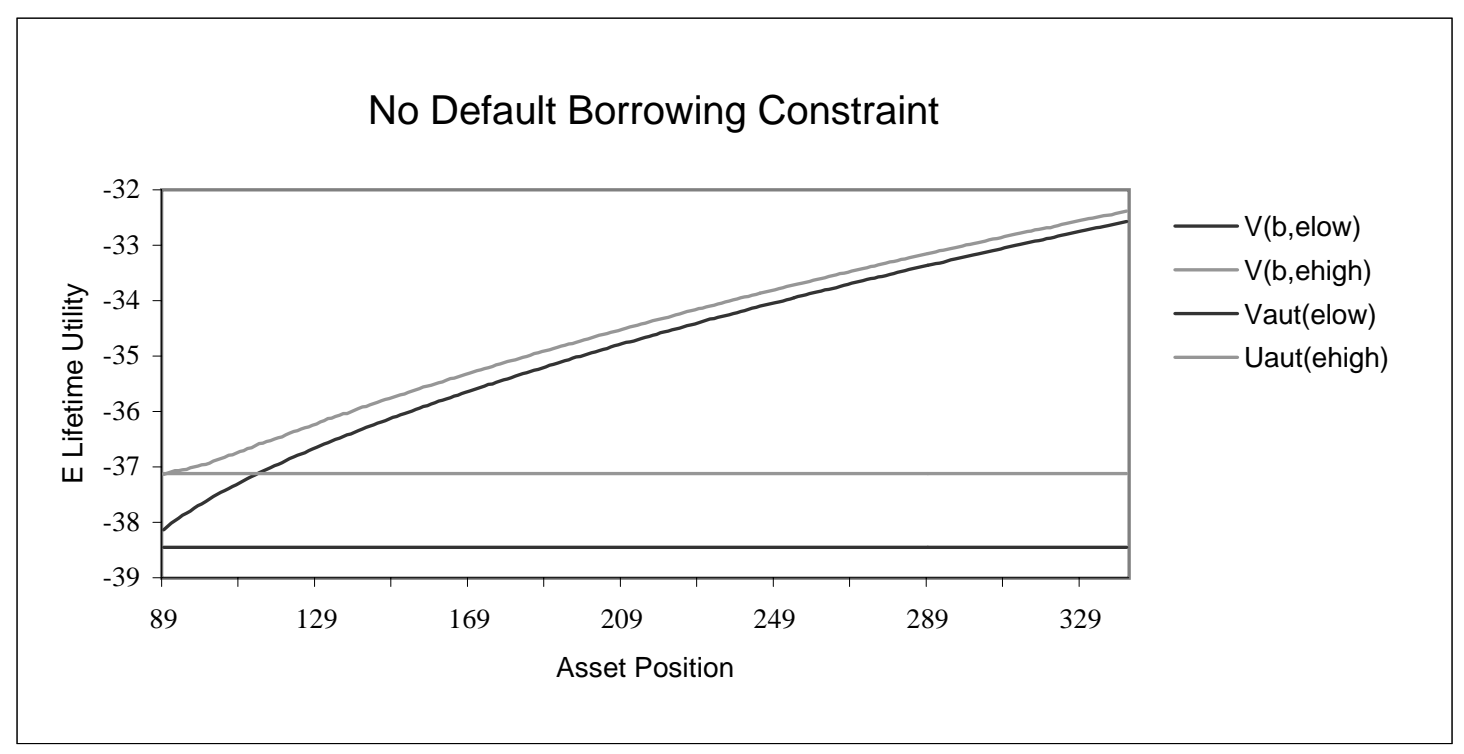


Figure 13. Limiting Distribution of Foreign Assets in the Economy with Participation Constraints (simulation with $\sigma=5 \quad$ )

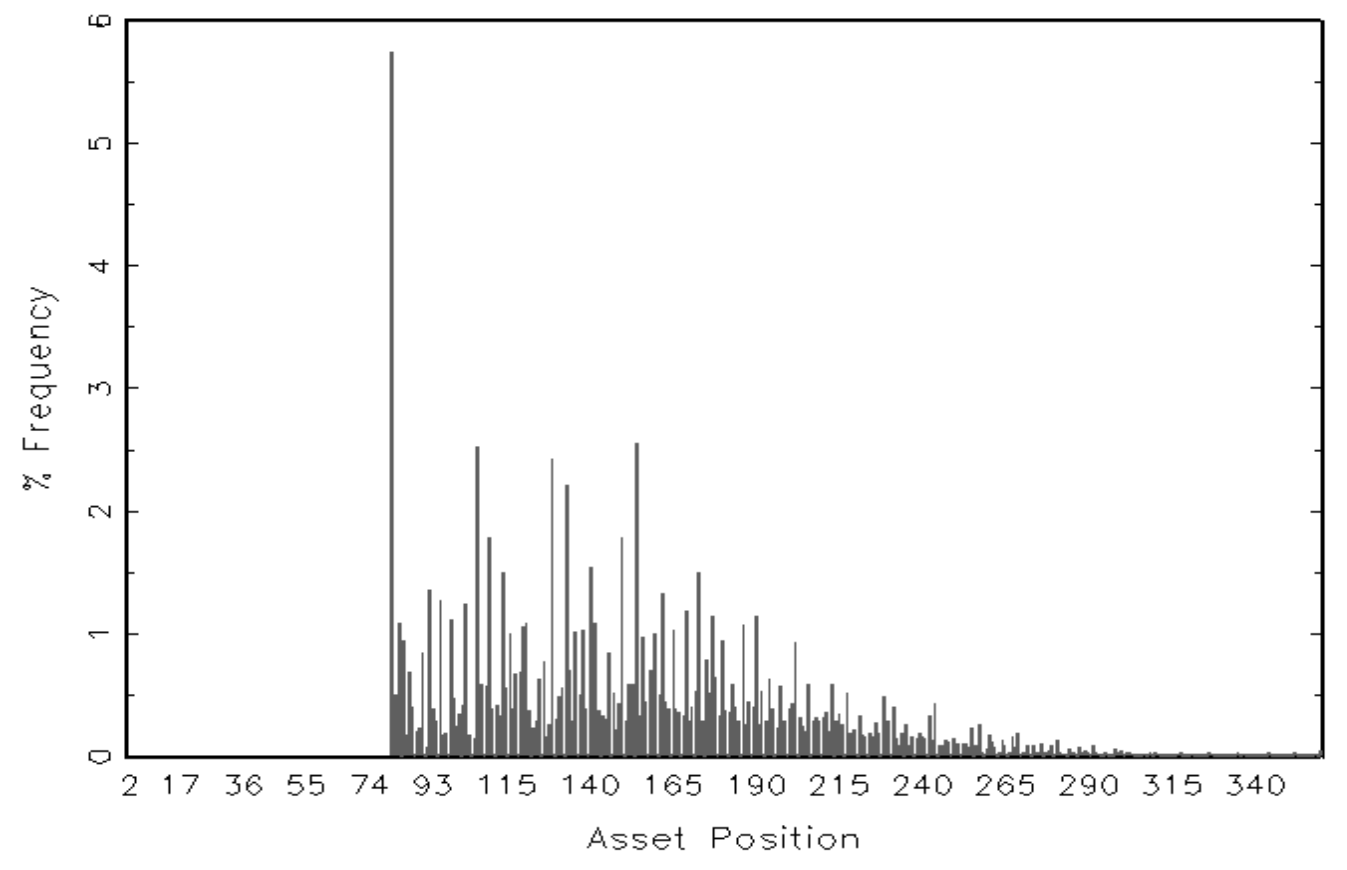


Figure 14. Impact Effects of A Shift from High Productivity to Low Productivity

\section{Experiment $1 \quad \sigma=5$}
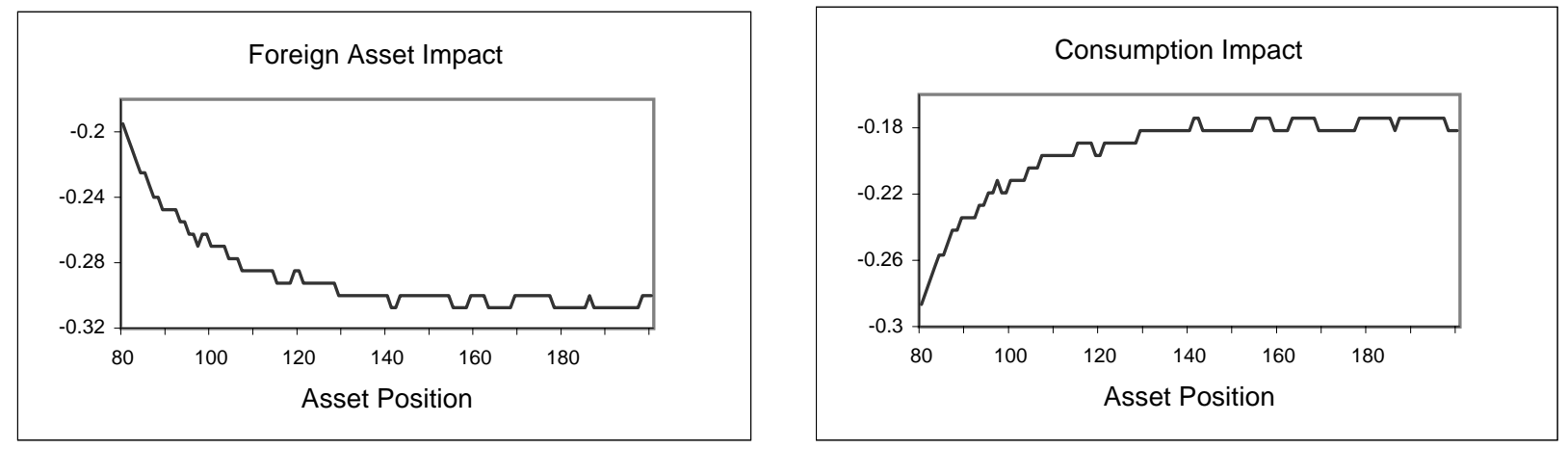

\section{Experiment $2 \quad \sigma=2$}
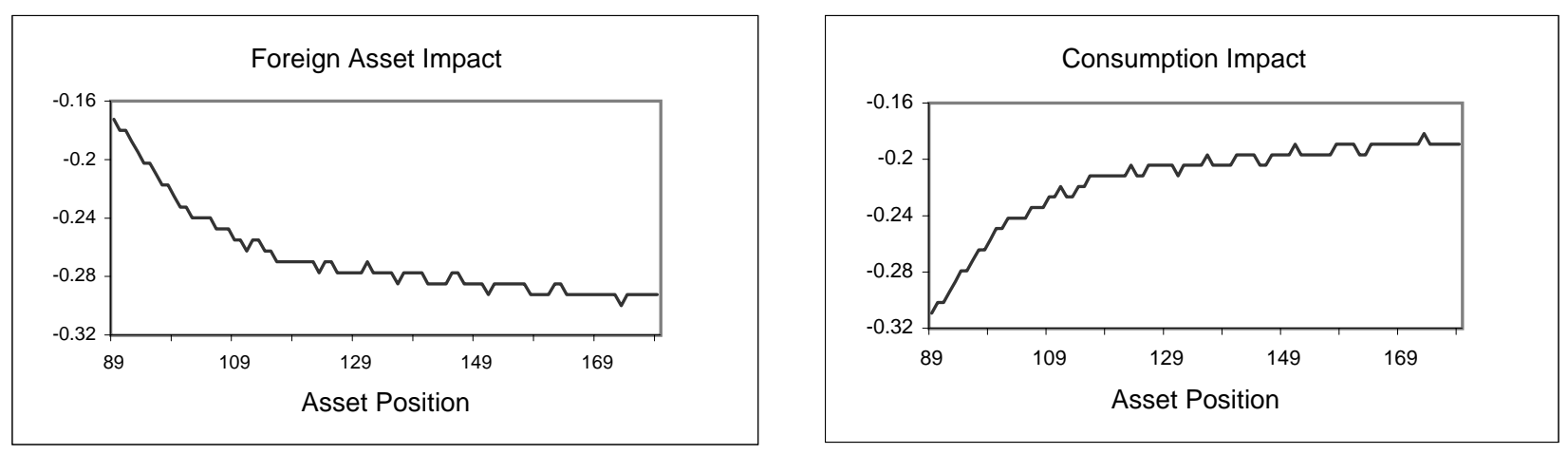